\title{
جواب ابن الشاط على نازلة في زمن الوباء.. قراءة في المستندات
}

\section{عبد الحميد الراقي}

جامعة محمد بن زايد للعلوم الإنسانية-أبوظبي

مركز الموطأ للدراسات والتعليم-أبوظبي زيدي

hamidraki10@gmail.com 


\title{
جواب ابن الشاط على نازلة في زمن الوباء.. قراءة في المستندات
}

\author{
عبد الحميد الراقي \\ جامعة محمد بن زايد للعلوم الإنسانية- أبوظبي المرائ

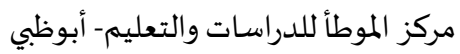 \\ hamidraki10@gmail.com
}

DOI: https://doi.org/10.31559/SIS2021.6.1.1 2021/6/27 2021/5/23 مراجعة البحث: 2021/6/20 قبول البحث البحث: 2010

يقصد هذا البحث إلى إبراز المستندات التي اعتمد عليها جواب الفقيه ابن الشّاط على نازلة وقعت زمن الوباء، وهي مستندات

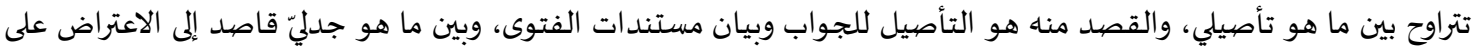
جواب الفقياء قاسم العقباني بخصوص النازلة. كما يسعى البحث -من خلال اختلاف الأجوبة- إلى التأكيد على أن الاجتهاد لم ينقطع عند الفقهاء رغم غياب المجتهد المطلق. الكلمات المفتاحية: النوازل؛ أصول الفقه؛ الاجتهاد؛ المذهب المالكي.

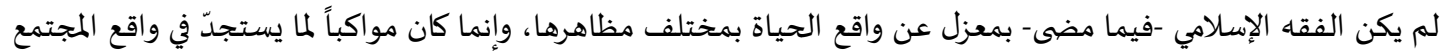

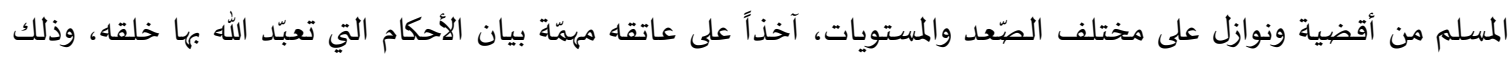
بمقتضى أمانة الاستخلاف القاضية بالرجوع إلى أهل الذكر، وبمقتضى الإرث النبوي، والقاضي بكون العلماء ورثة الأنبياء، وقد تقرر

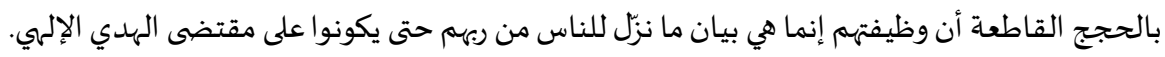

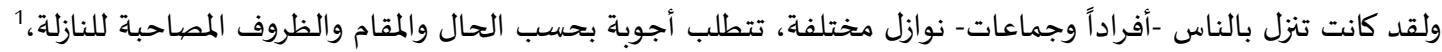

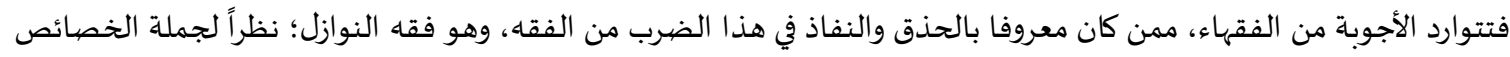

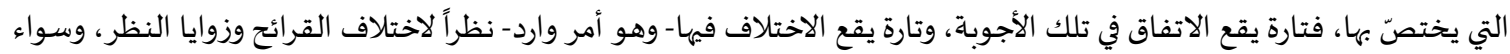

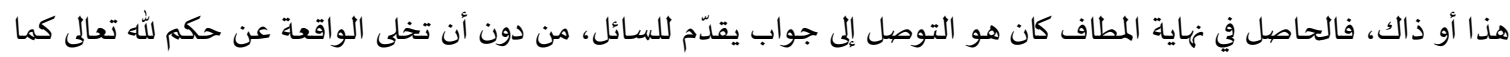
تقرّر في الأصول. وقد كان من النوازل التي أوردها صاحب المعيار3 نازلة تتعلق بموضوع الوصايا في زمن الوباء، وقعت في زمن الوباء، وتعدّدت

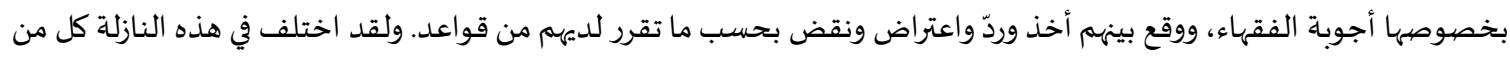

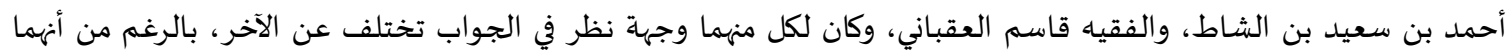

1 كان فقه النوازل يتفاعل مع كل ما يستجد من القضايا من مختلف المجالات، ينظر في هذا الصيدد مقال الكاتب جوستان ستيرنس. J. Stearns. The legal Status of Science in The Muslim World in The Early Modern Period: An Initial Consideration of Fatwas from Three Magribi Sources. In: The Islamic scholarly tradition, studies in history, law, and thought in honor of Professor Michael Allan Cook, p: 265-290. BRILL, 2011.

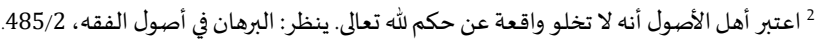

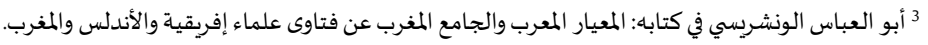

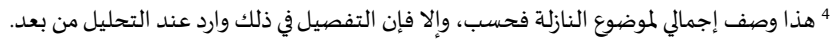


ينتميان إلى المذهب نفسه، وهو المذذهب المالكي، وهو ما يثبت أن التّمذهب بالمذهبب الواحد لا ينفي الاجتهاد عن الفقيه المقلّد؛ّ لأن

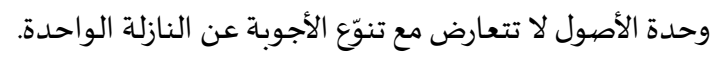

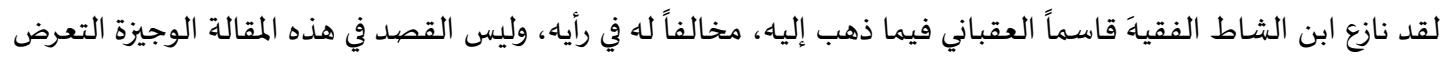

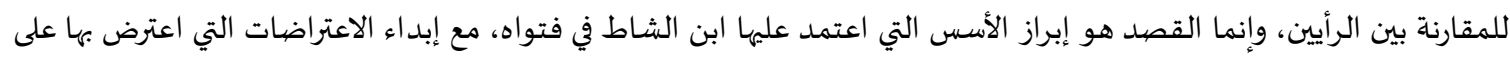

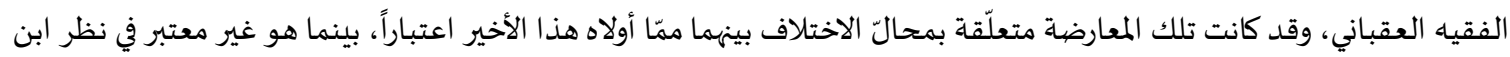

ما هي مستندات الفتوى عند ابن الشاط باعتباره أحد من تعرّض للجواب عن هذه النازلة؟ وما هي مراتها من حيث النيث الاستعمال

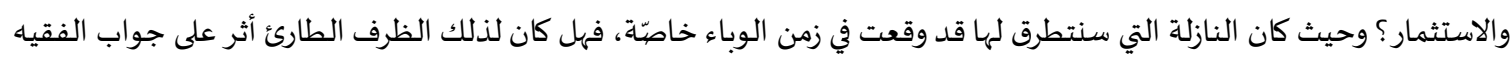

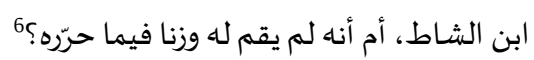

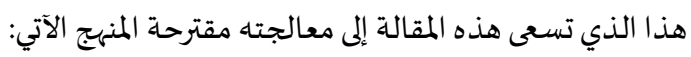

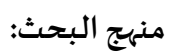
المنهج المقترح لهذا الموضوع هو المنهج التحليلي القاصد إلى استنباط المستندات التي اعتمدها جواب ابن الشاط، وتحليلها وبيان وجاه استثمارها في النازلة.

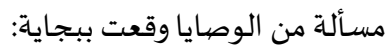

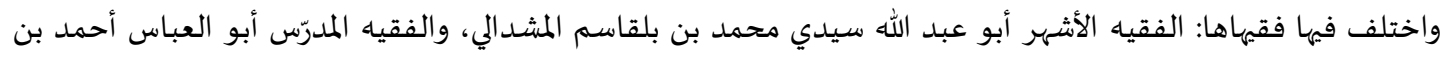

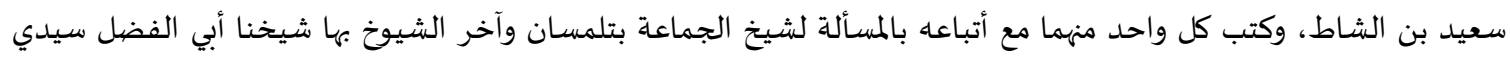

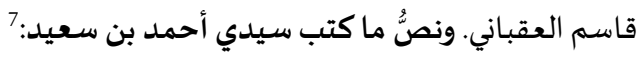

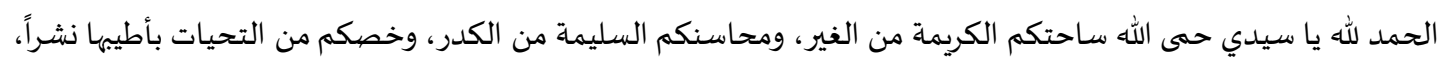

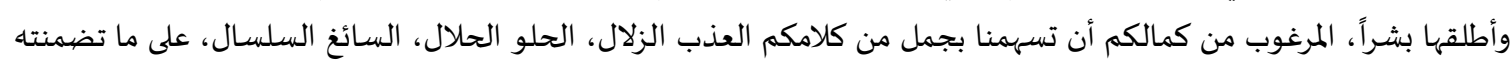

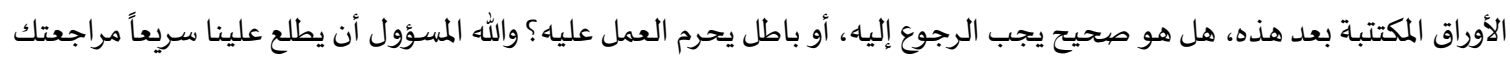

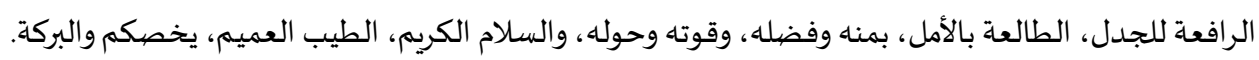

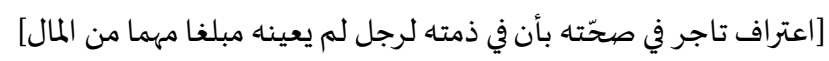

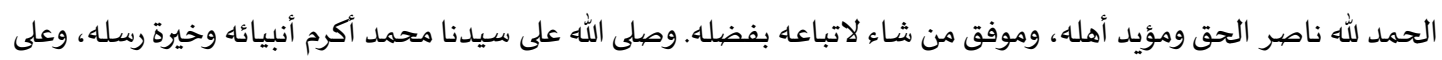

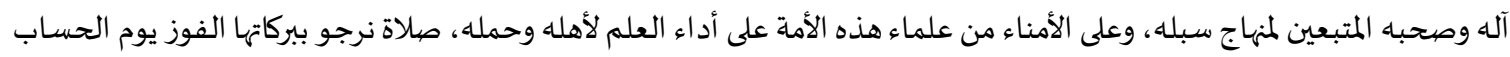
من فضيحته وصوله.

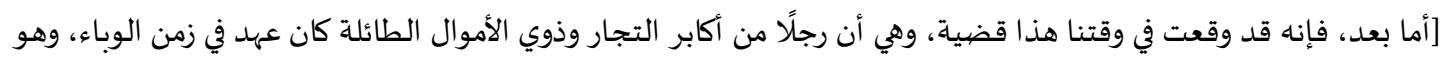

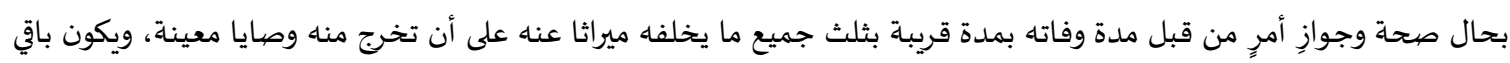

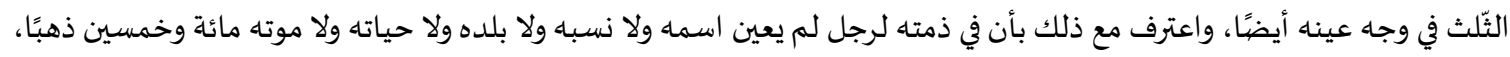

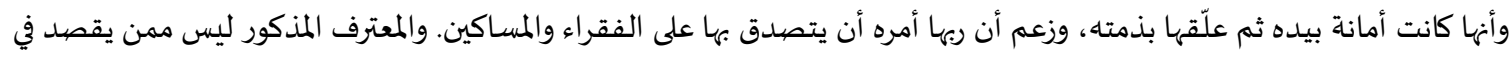

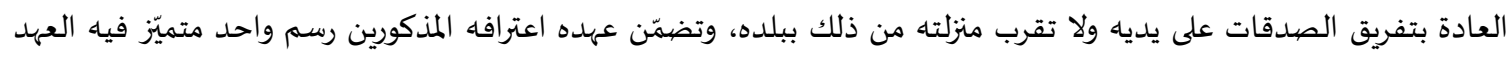

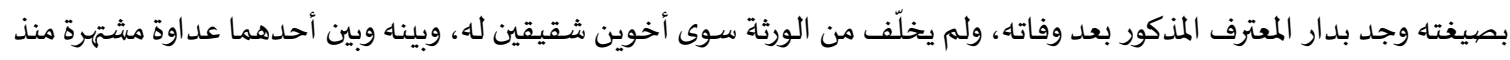

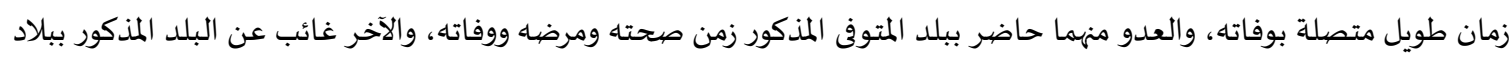

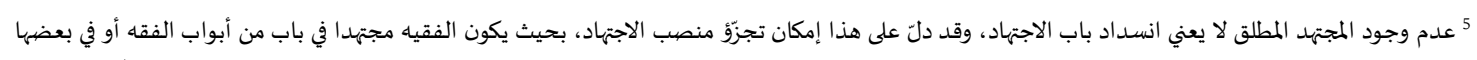

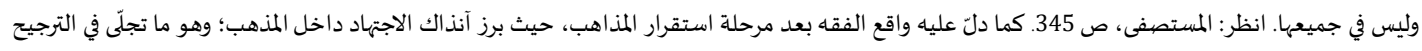

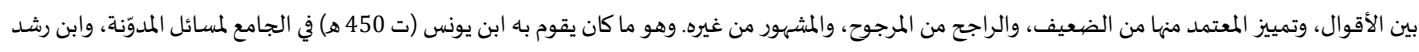

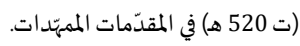

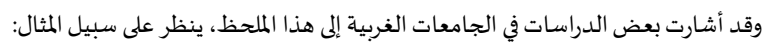
A. FIKRI, Rethinking the Taqlid Hegemony: An Institutional, Longue-Duree Approach, Journal of American Oriental Society, 126.4 (2016). P,
803-805. 
المشرق منذ نحو عامين اثنين متقدمين عن وفاة العاهد المذكور. وهذا حاصل ما تضمّنتته القضيّة، وقد اختلّ فقهاء بلدنا بجاية

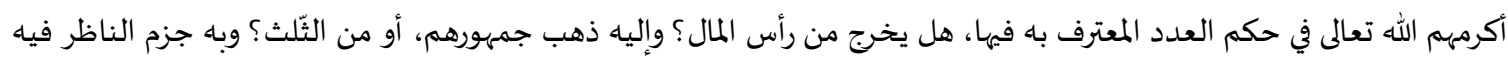

مصرّحا بتخطئة مخالفياه وتوهيمهم]. ولما سمعت ما صهدر منه من التّخطئة والتّوهيم، والتّضعيف لمستندهمه والتّستيم، وتحقّقت أن قولههم في المسألة هو الجاري

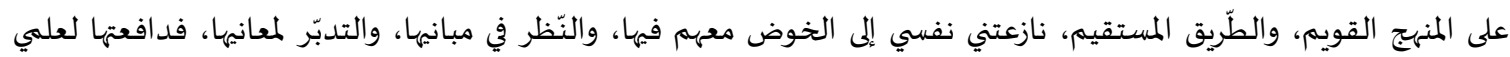

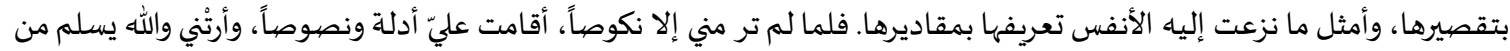

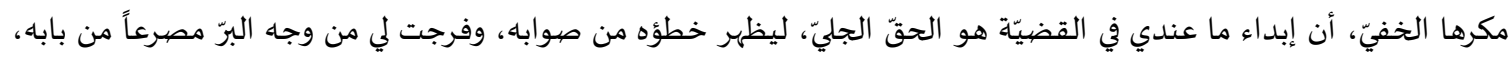

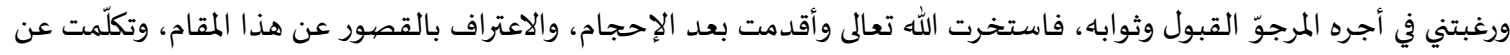

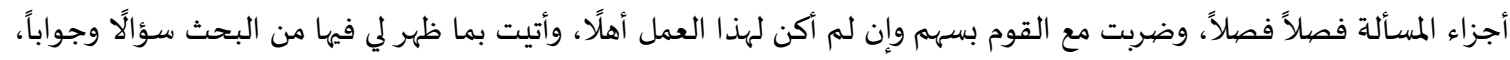

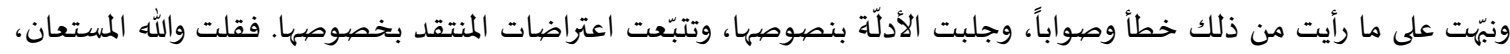

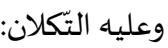

اعلم أن الإقرار في الصّّحّة حكمه اللزوم والخروج من رأس المال، هكذا نص عليه أئمّتنا. قال ابن الحارث: وكل من أقرّ في صحّتـه

بدين فإنّا يلزمه إقراره كان المقرّ له أجنبيًّا أو وارثًا.

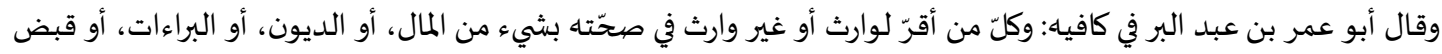

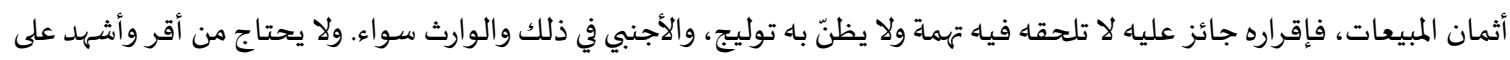

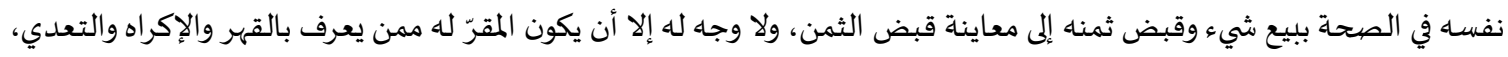

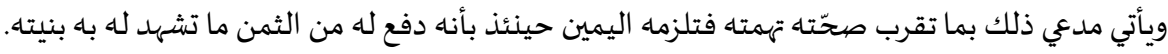

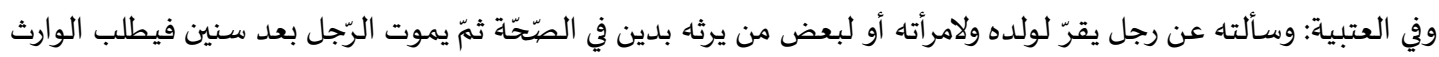

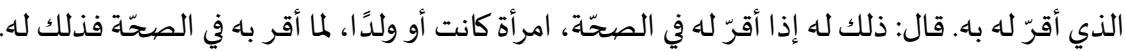

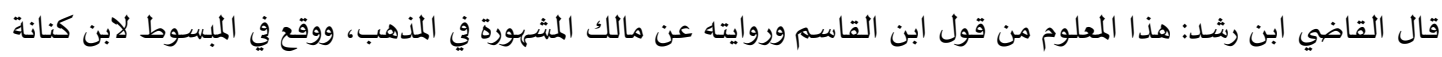

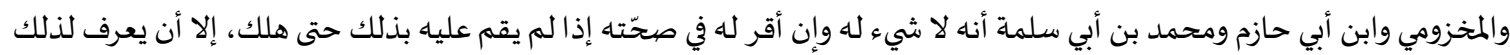

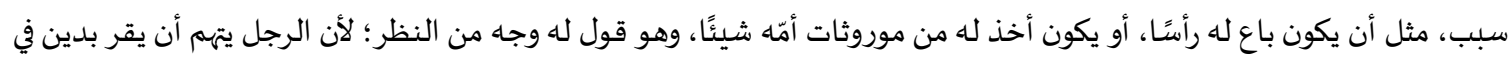

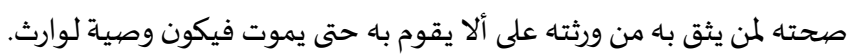

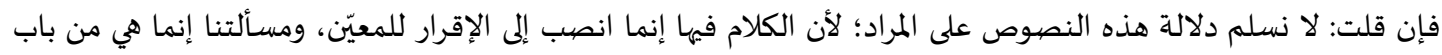
الإقرار لغير معيّن، والإقرار للمعيّن أقوى.

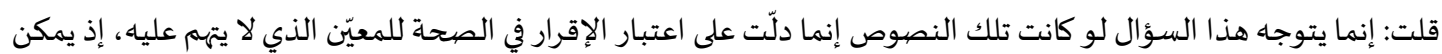

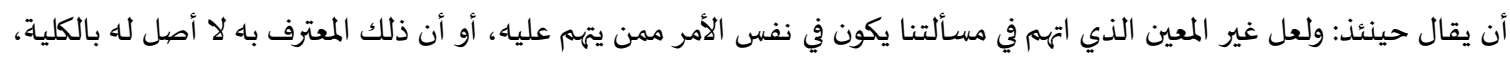
وإنما أراد المقر إخراجه عن نفسـه من رأس ماله بعد موته. وأما حيث دلت النصيوص المتقدمة على اعتبار الإقرار في الصحة للولد

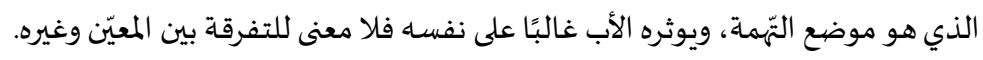

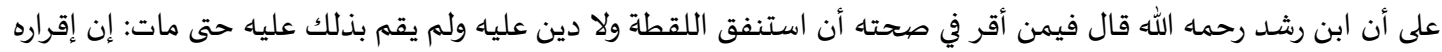

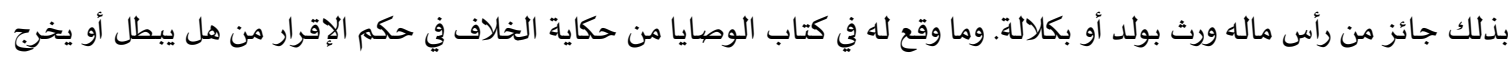

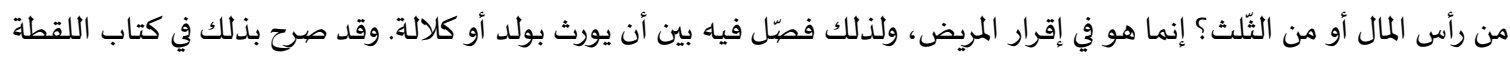

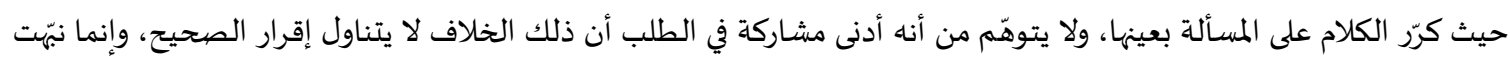
على هذا لتمسك بعض الناس باه في المسألة. فإن قلت: حاصل ما ذكرته إعمال إقرار الصحيح حيث لم يتهم عليه، وذلك مؤذن بإلغاء التهمة في باب الإقرار بالصحسة، لكن

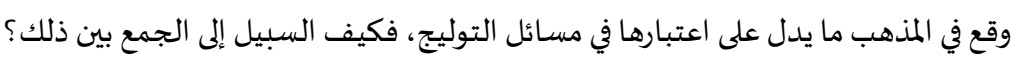

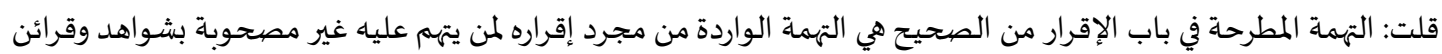

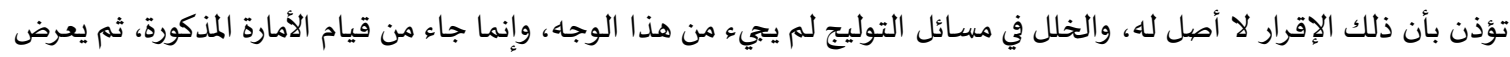
لتلك الأمارات القوة والضعف أو التعارض أو التوسط، فينشأ عن ذلك الاتفاق على اعتبارها تارة، والاتفاق على إلغائها أخرى،

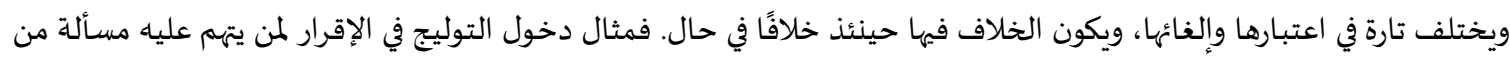




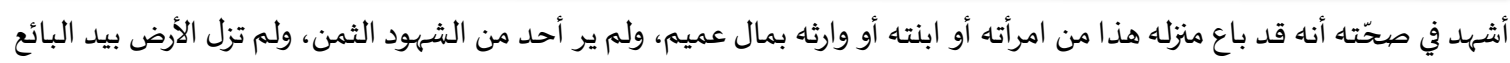

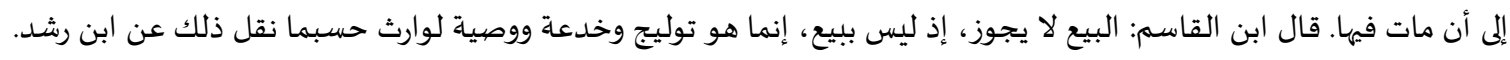

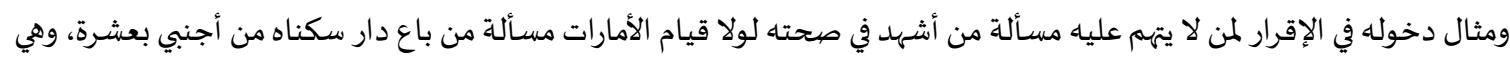

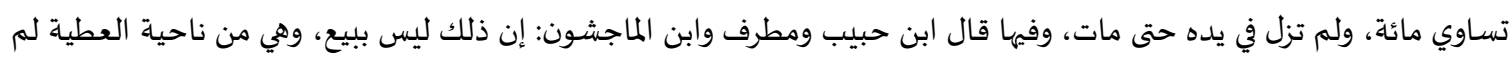

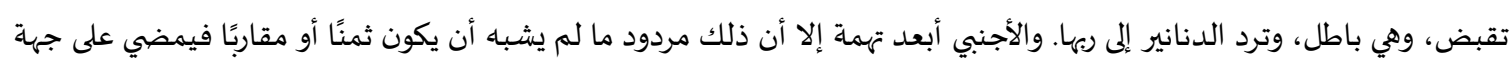

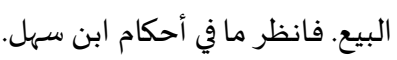

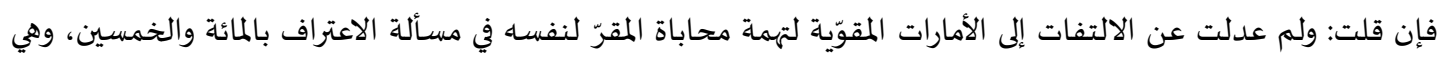

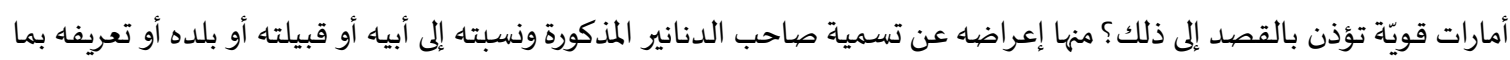

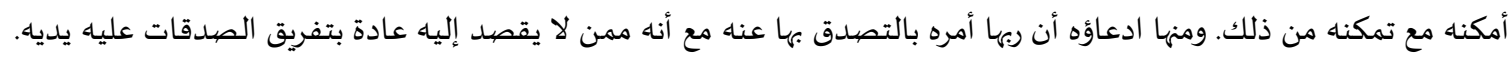

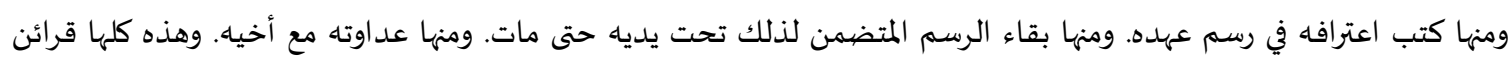

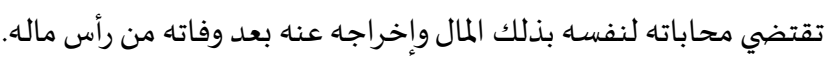

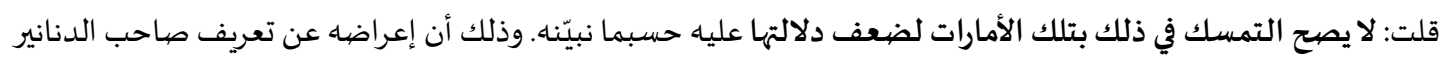

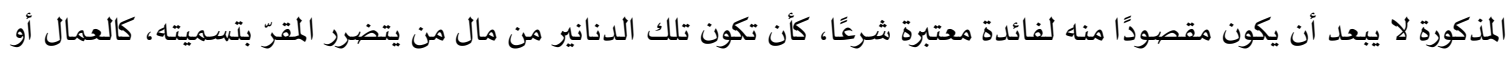

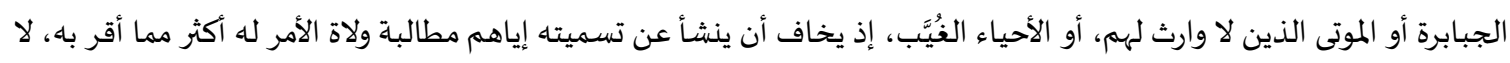

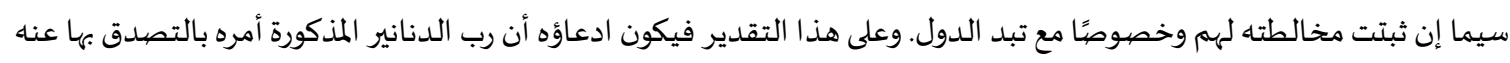

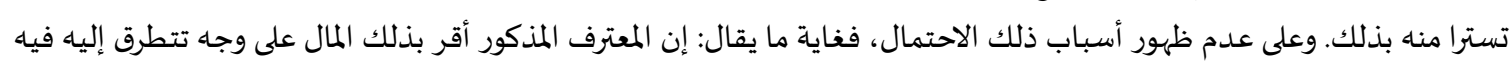

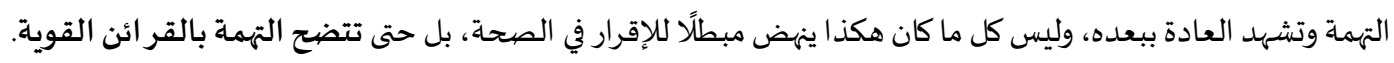

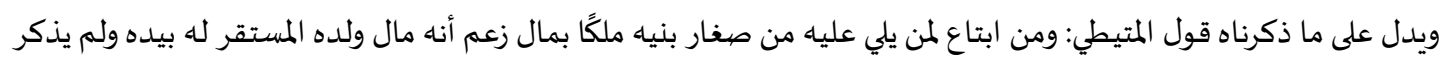

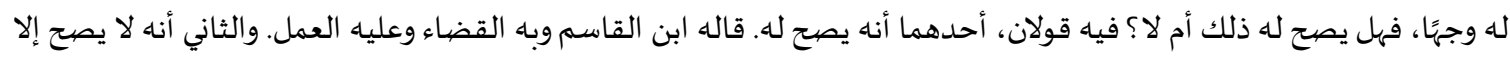

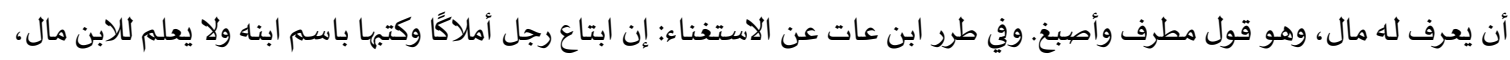

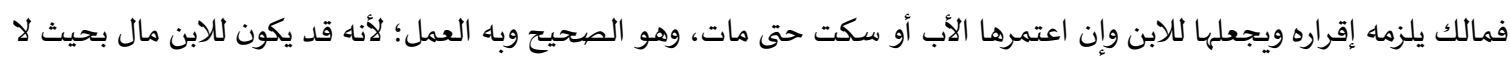

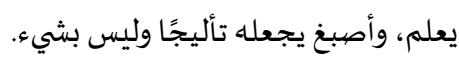

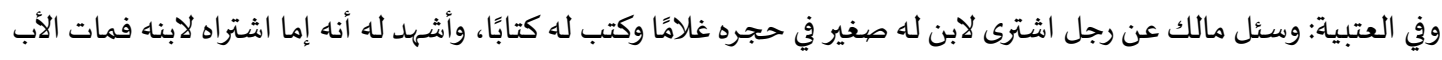

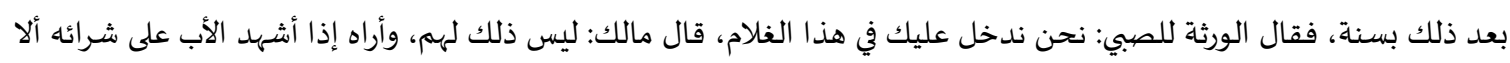

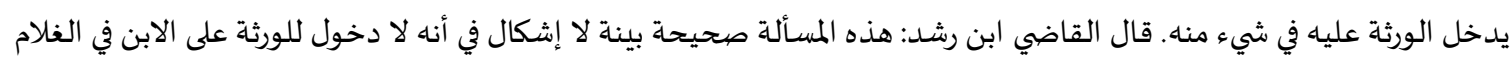

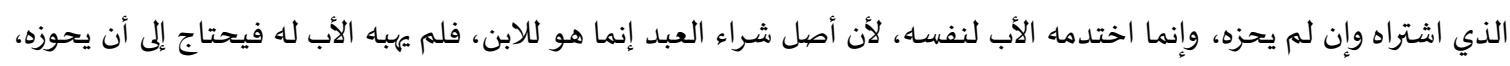

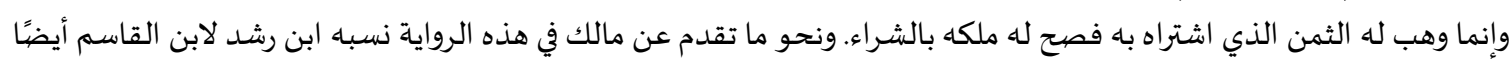

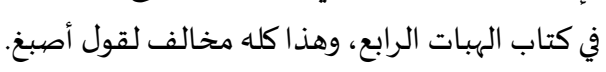

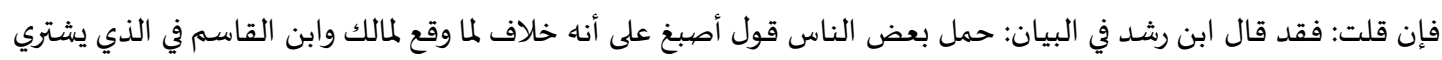

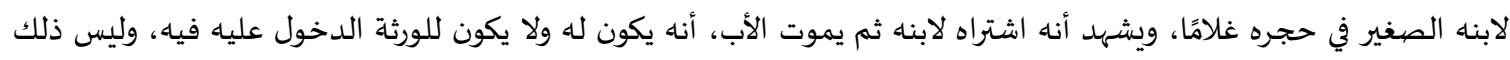

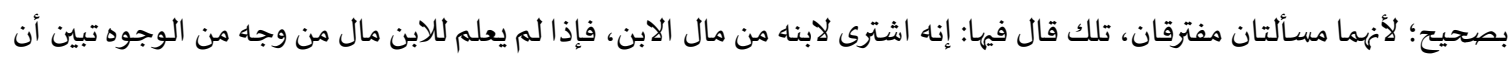

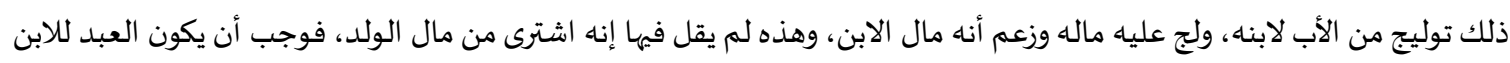

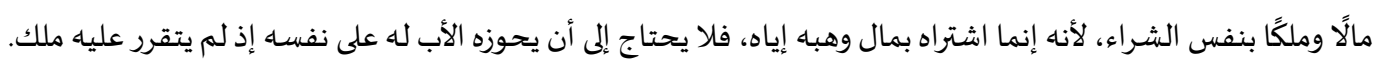

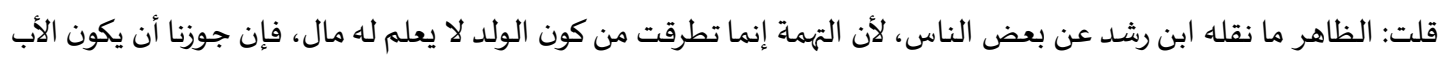

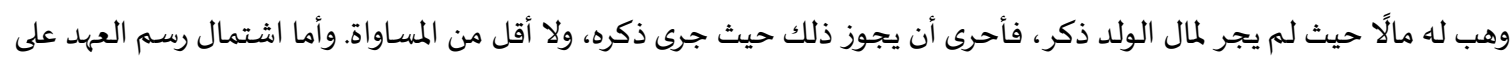

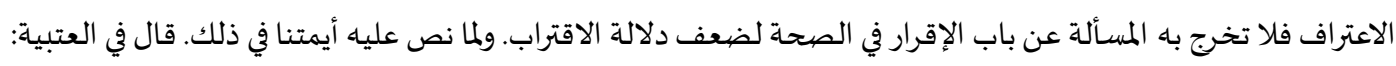

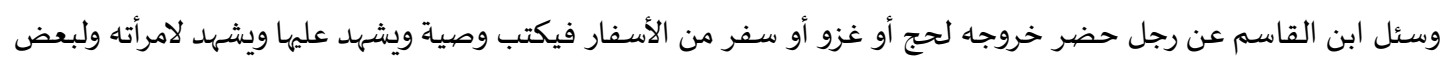

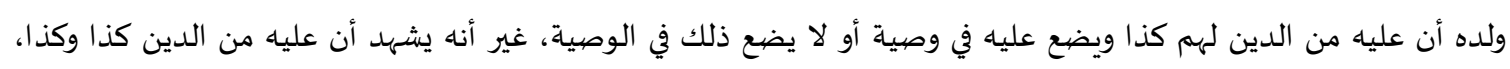

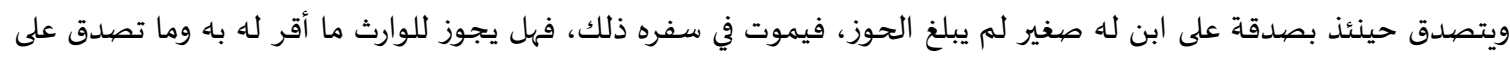

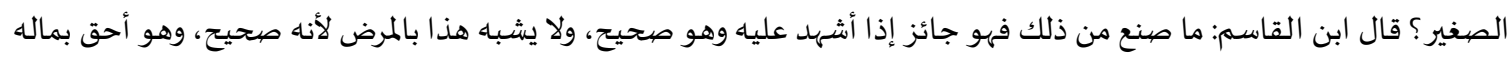

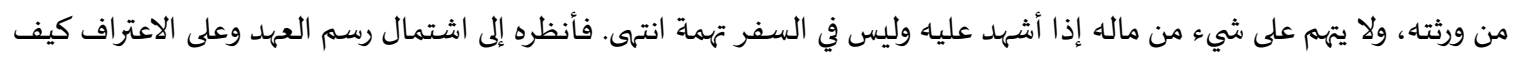




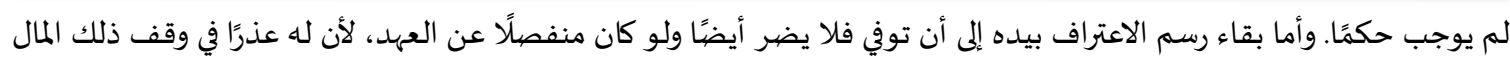

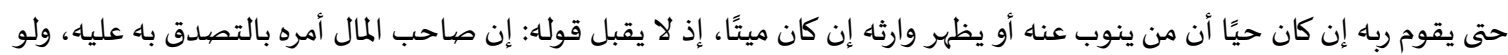
فعل لضمن إلا أن يصدقه مستحقه.

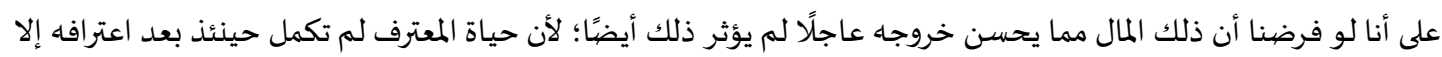

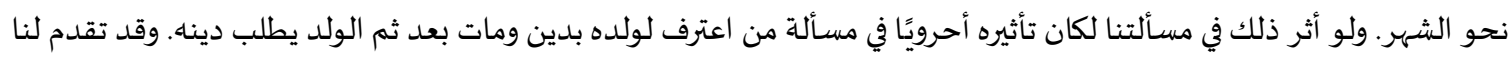

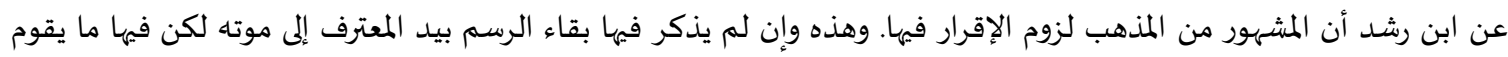

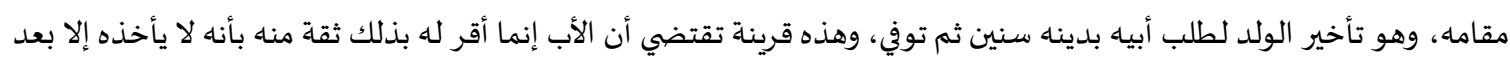

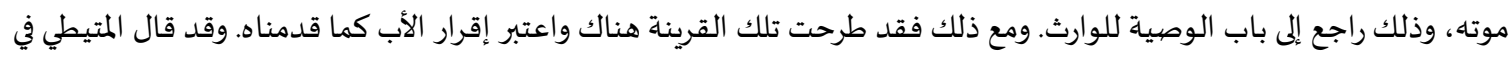

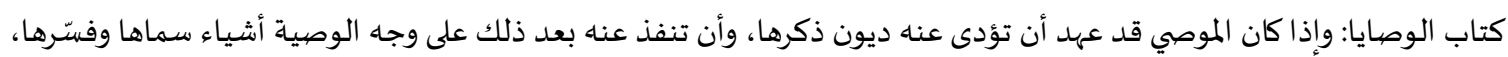

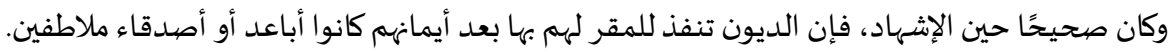

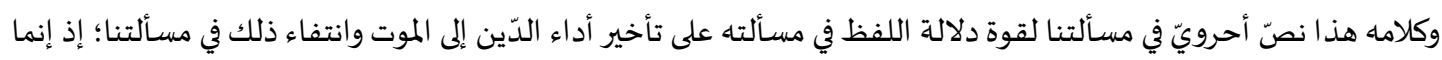

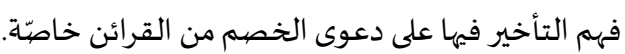
فإن قلت: كلام المتيطي في الإقرار للمعين. ومسألتك في الإقرار للمجهول، ولا يلزم من إعمال الإقرار في تلك إعماله في هذه لقوة الأول وضعف الثاني.

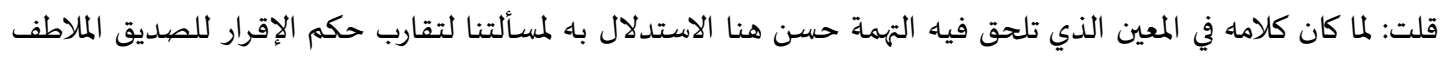

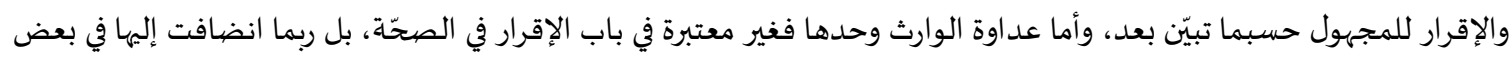

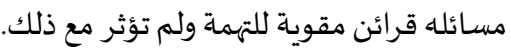

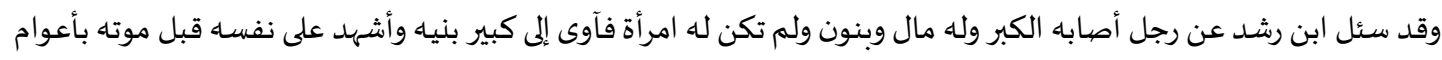

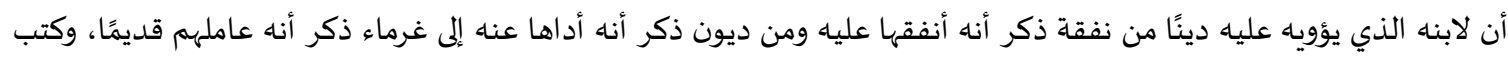

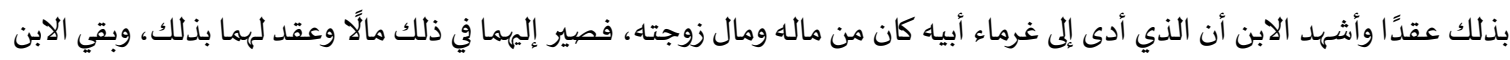

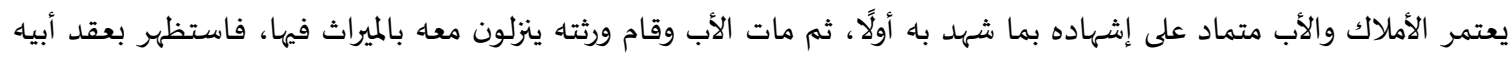

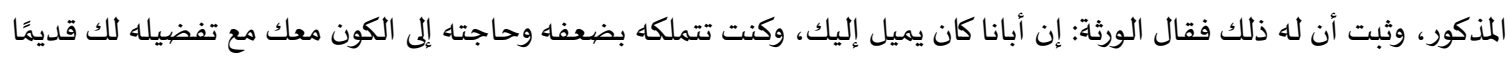

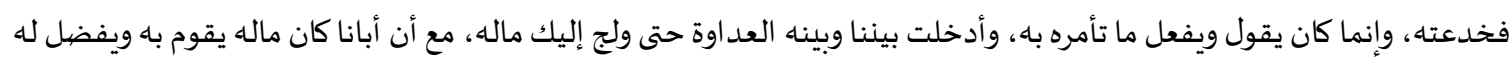

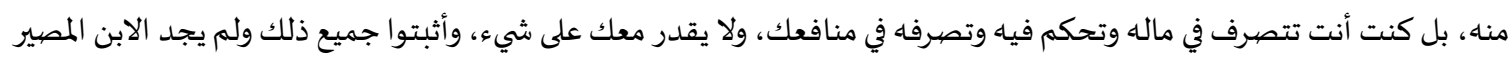

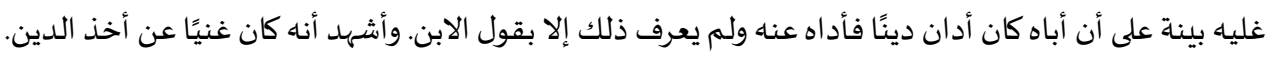

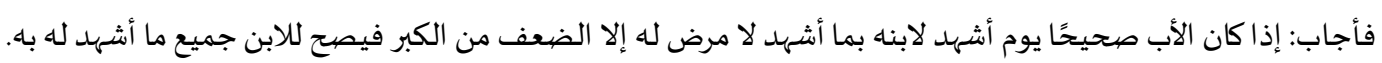

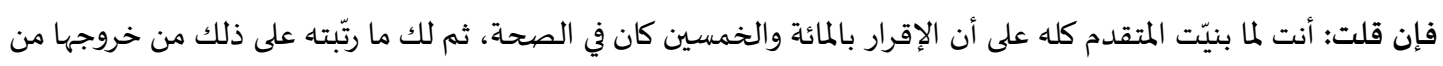

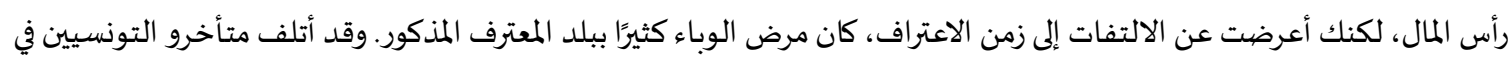

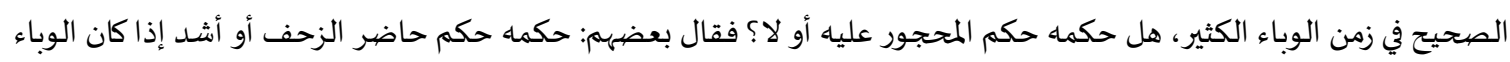

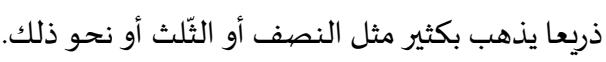

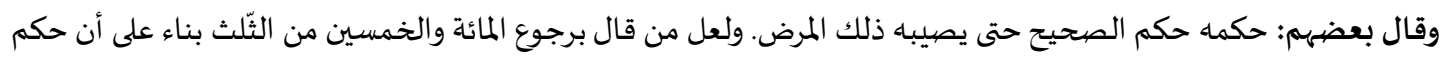

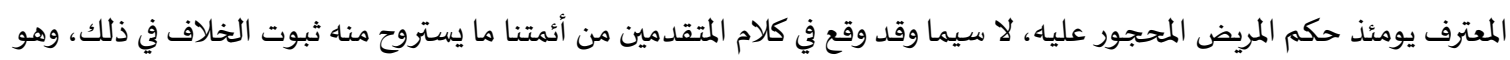

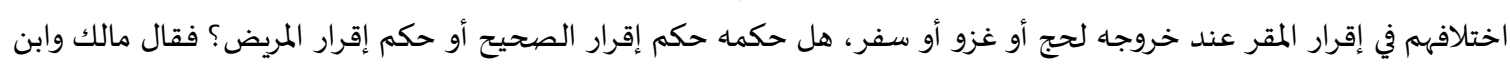

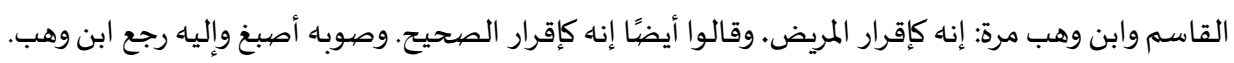

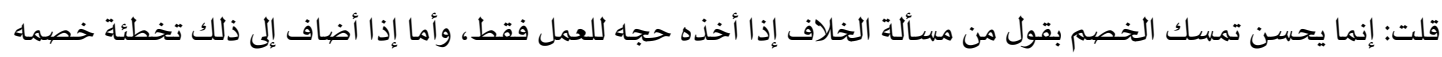

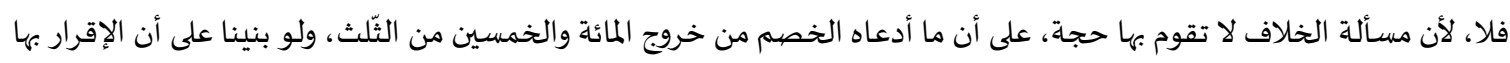

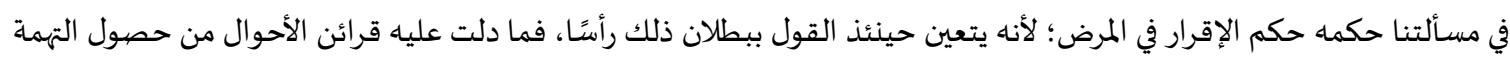

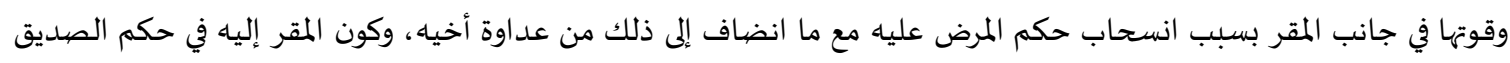
الملاطف، حسبما يتبين بعد. 


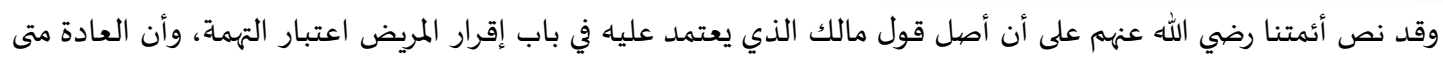

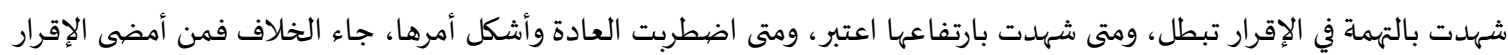

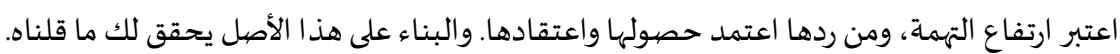

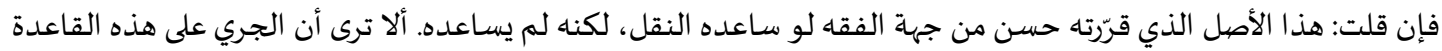

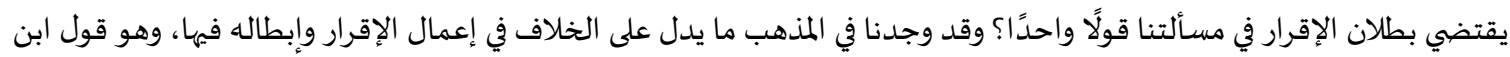

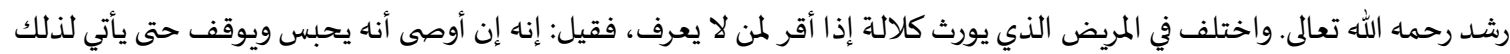

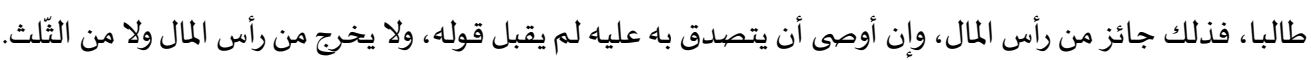

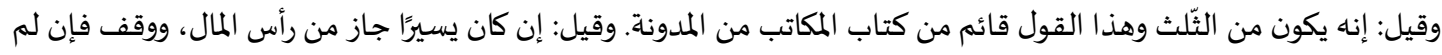

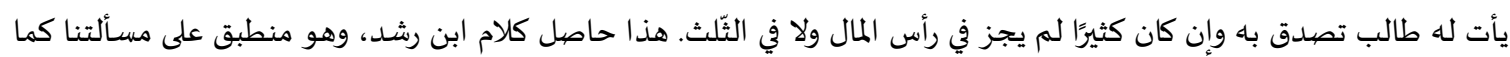

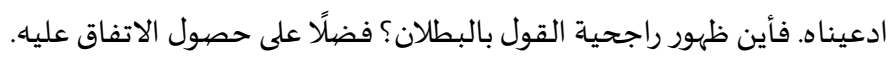

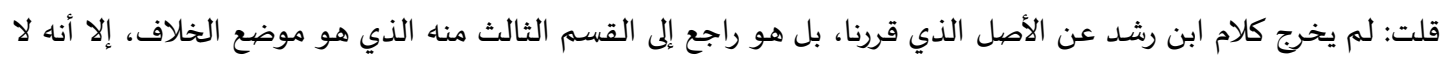

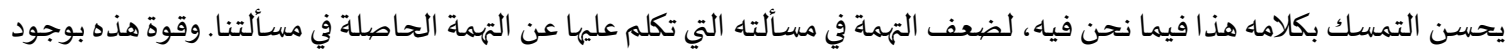
العداوة المذكورة.

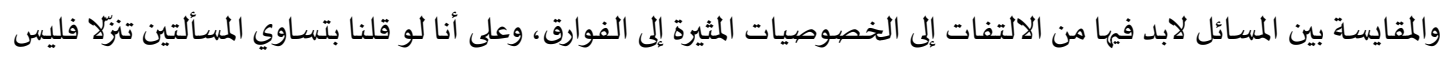

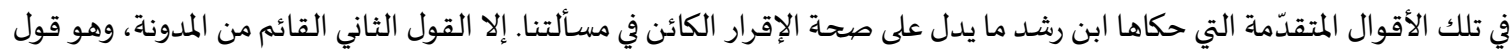

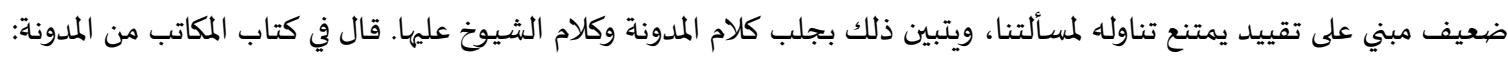

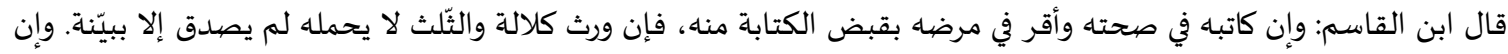

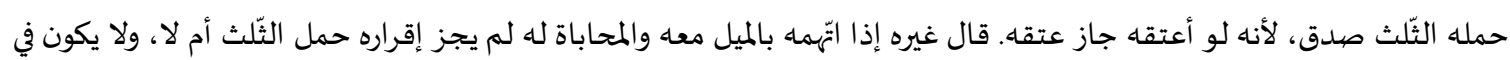

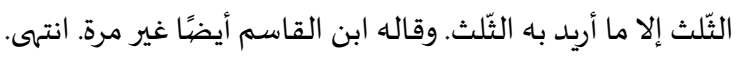

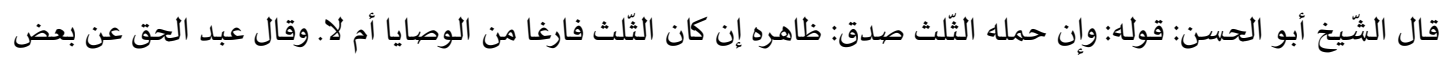

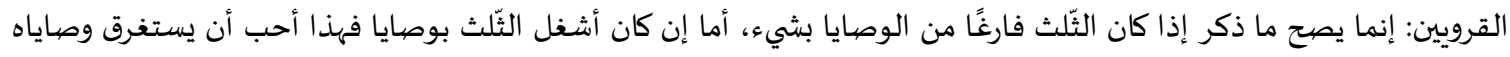

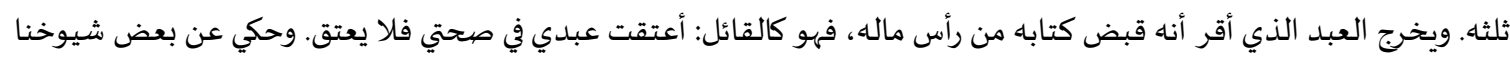

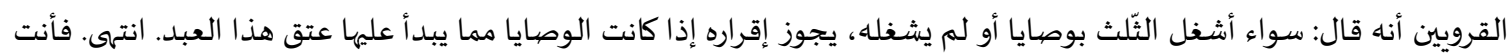

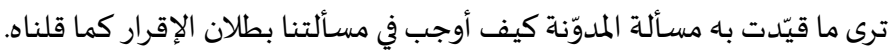

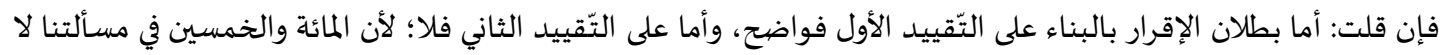

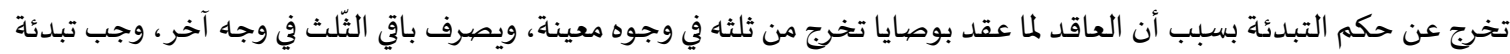

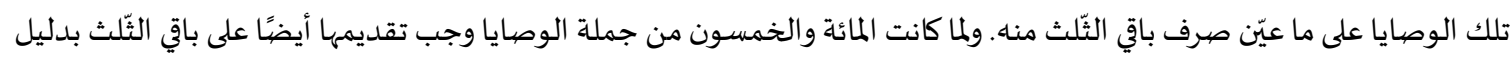

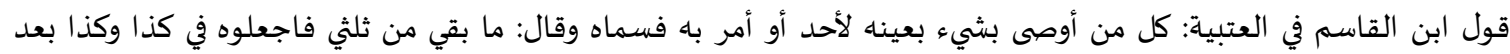

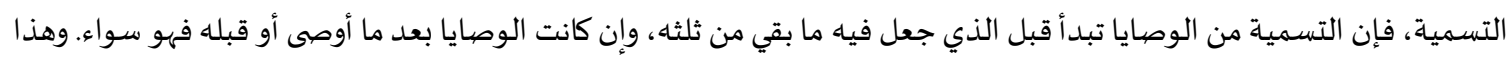

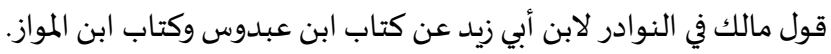

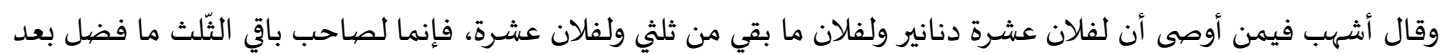
العشرين وبعد كل وصية. وقاله مالك. قلت: هذا حجة الخصم، وهي لا تقوم على ساق، لأن التبدئة في مسألة العتبية وكتاب ابن المواز إنما جاءت من جهة لفظ العاقد

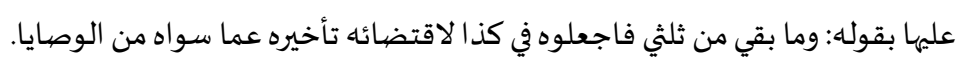

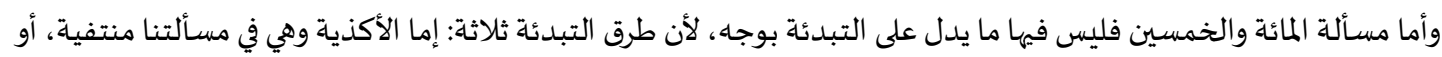

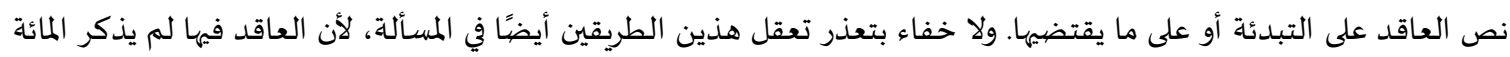

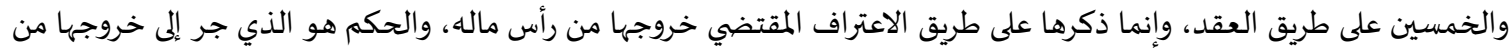

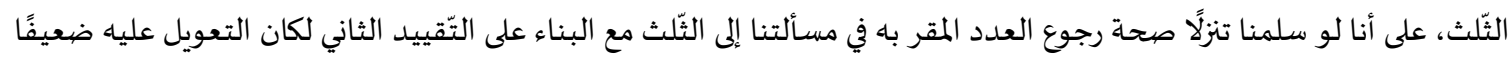

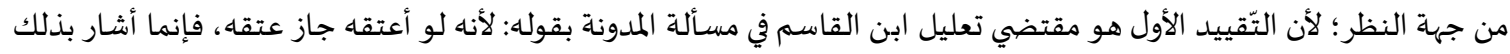

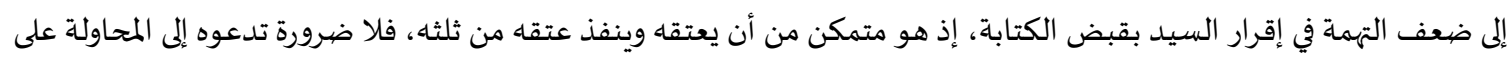
عتقه بواسطة الإقرار بالقبض. 


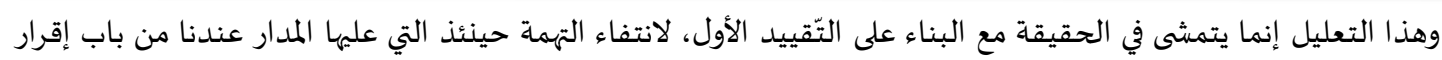

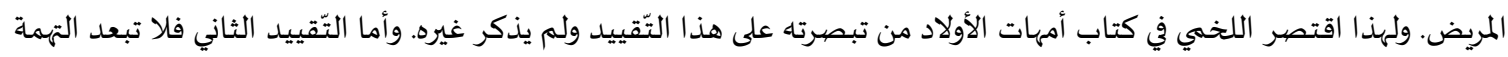

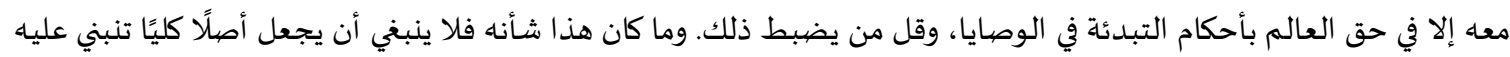

فإن قلت: ظاهر المدونة في مسألة المكاتب المذكورة الإطلاق والعمل بظاهرها كاف.

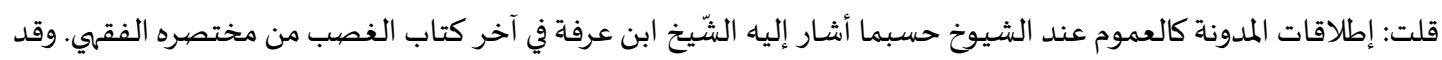

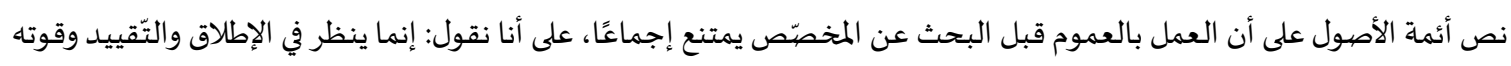

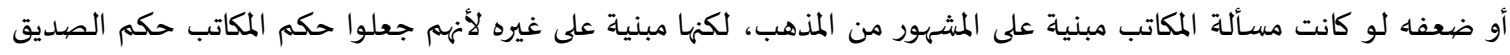

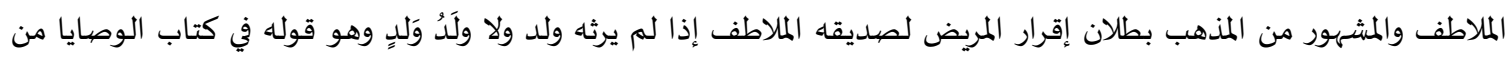

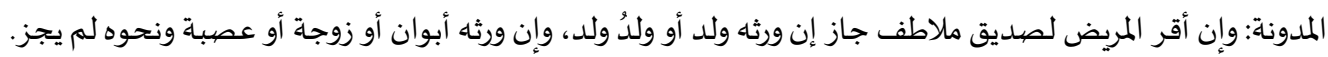

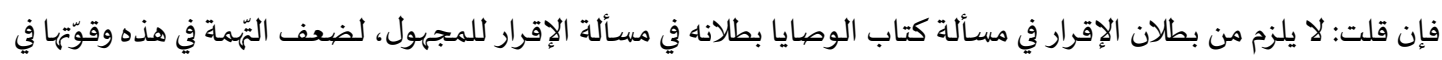

تلك.

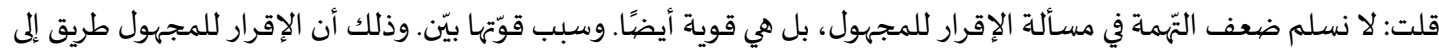

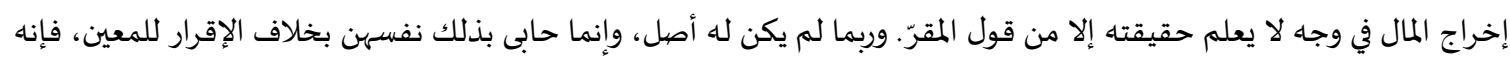

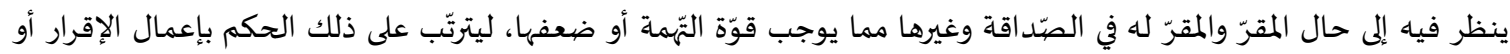

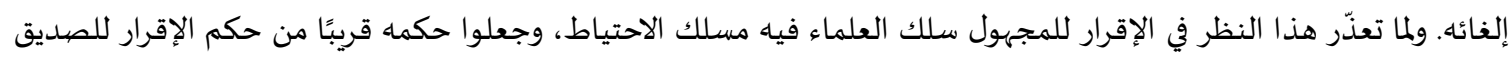
الملاطف.

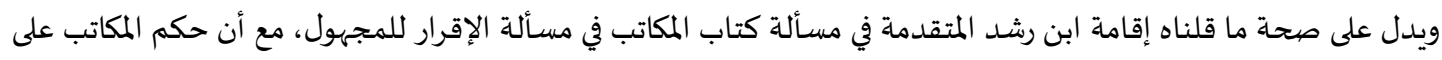

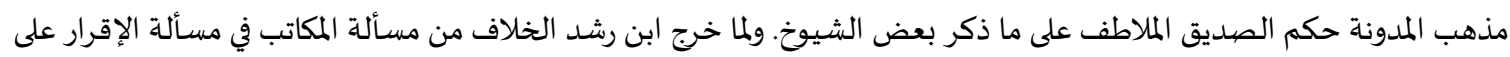
تساوي المسألتين عنده في التهمة.

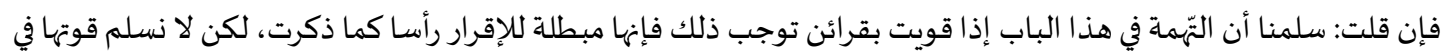

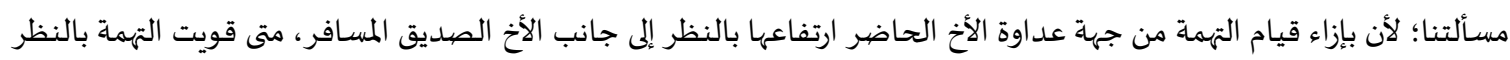

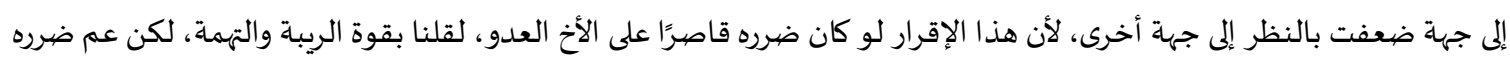

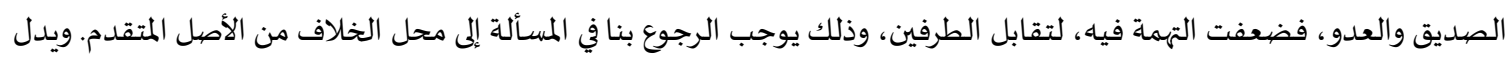

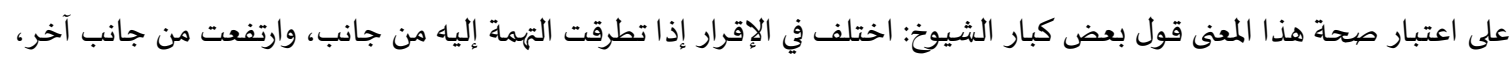

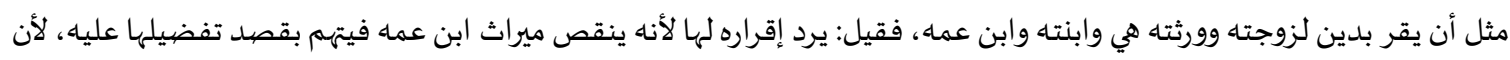

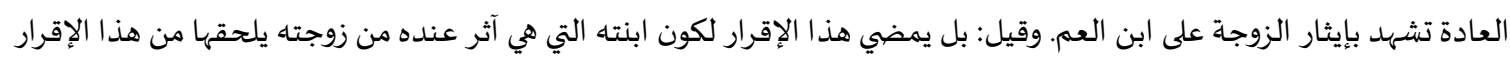

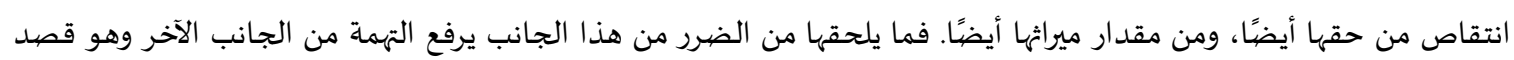
الضرر بابن عمده.

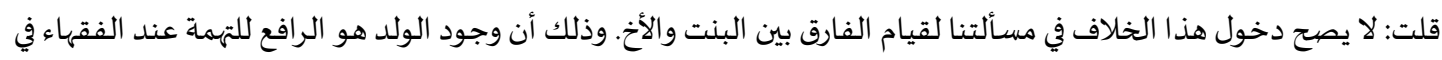

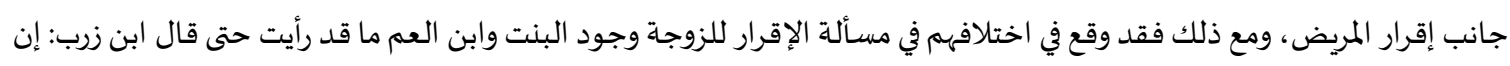

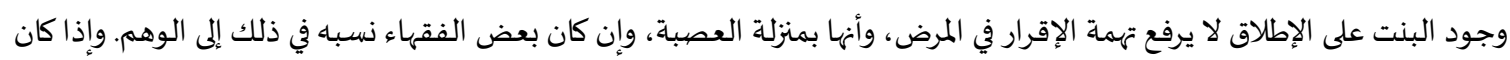

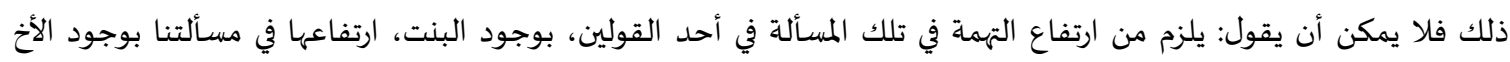

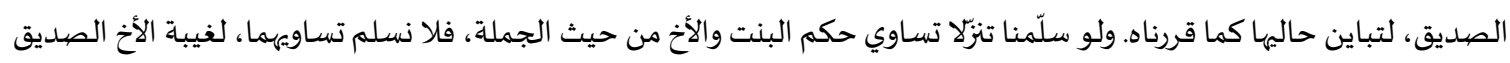

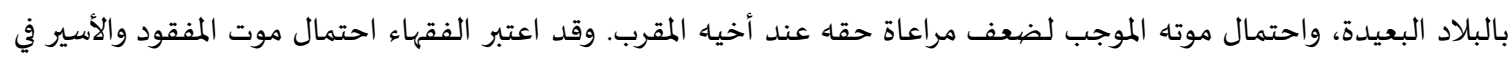

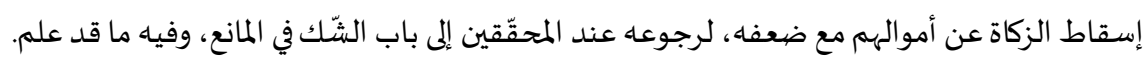

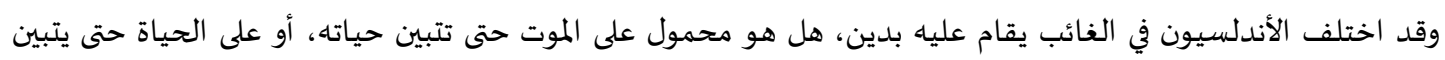
موته ف فانظر في أحكام ابن سهل.

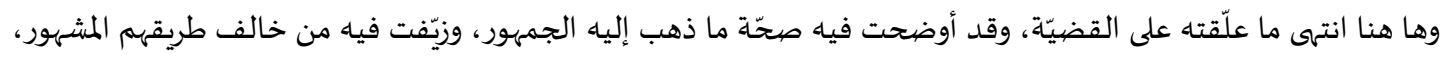

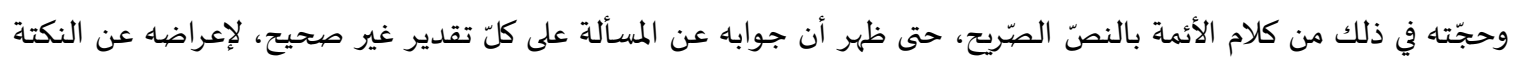

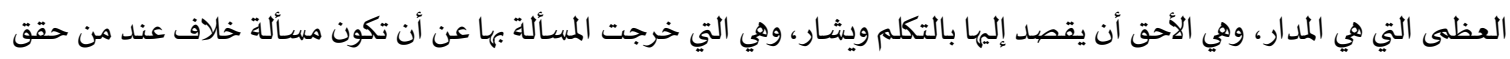




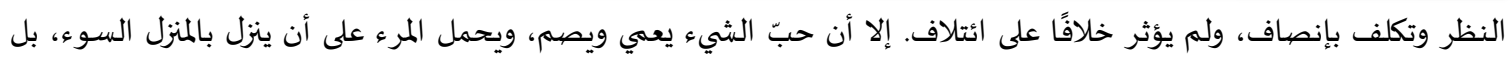

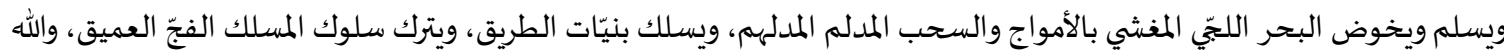

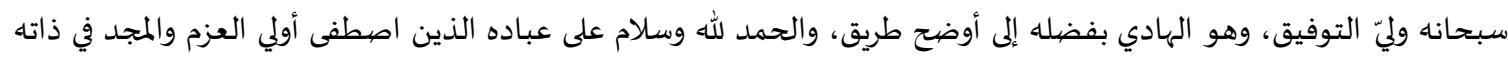

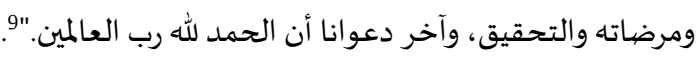

\section{موضوع النازلة وعناصرها:}

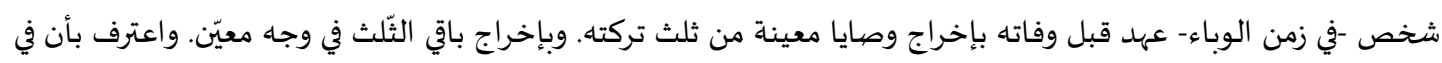

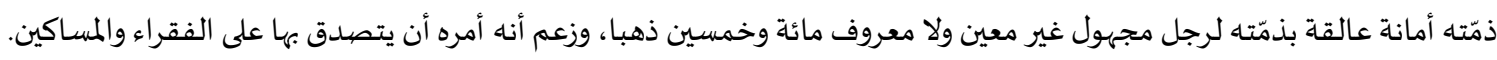

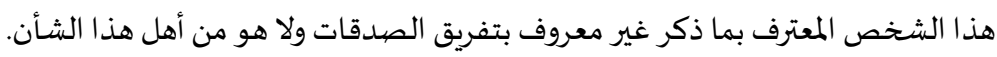

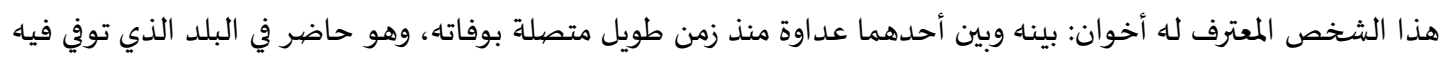

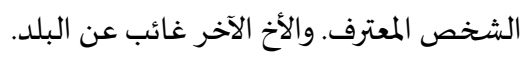

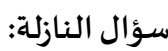
هل القدر المعترف باه- وهو مائة وخمسون ذهبا- تخرج من رأس المال، وهذا الذي ذهب إليه الأغلب؟ أو تخرج من الثّلث، وهو

$$
\begin{aligned}
& \text { الذي ذهب إليه العقباني المخالف في المسألة؟ } \\
& \text { أولاً: مستندات الجواب ومداركهـ: }
\end{aligned}
$$

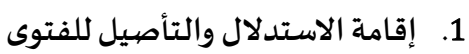

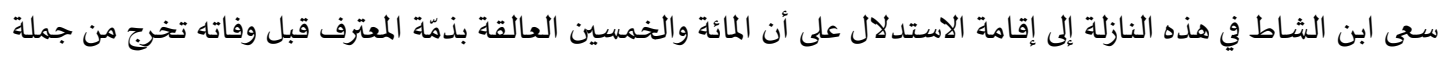

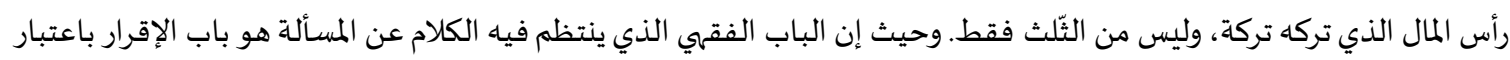

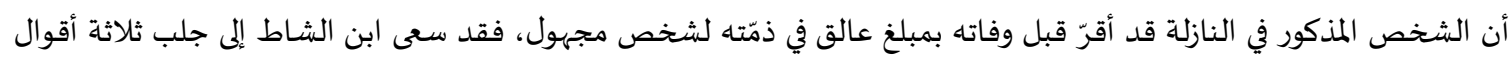

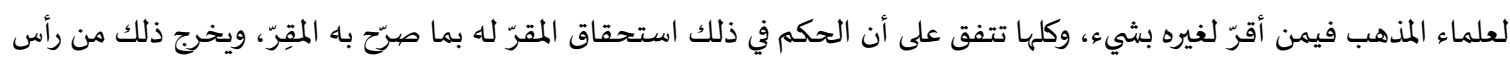

عدول ابن الشاط عن إيراد الأدلة من القرآن والسنة وآثار الصحابة لا يعني أن ما اختاره من أقوال مذهبية خال عن الدليل،

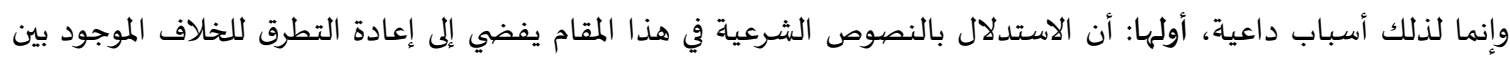

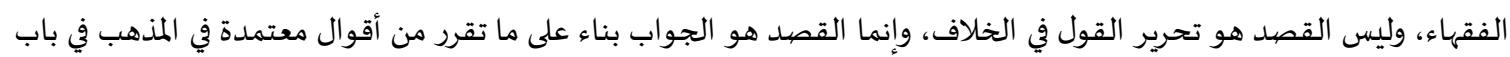

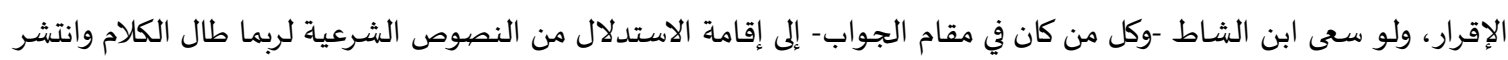

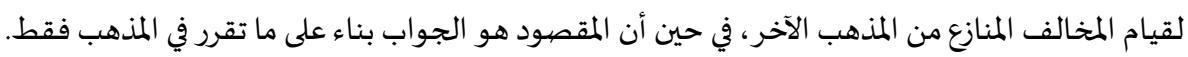

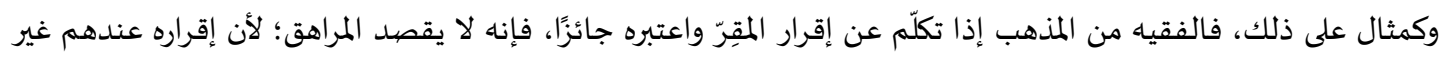

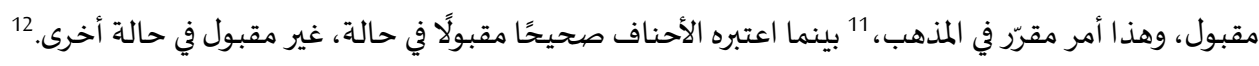

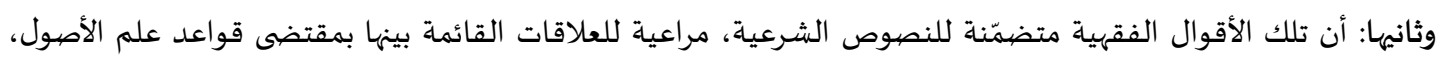

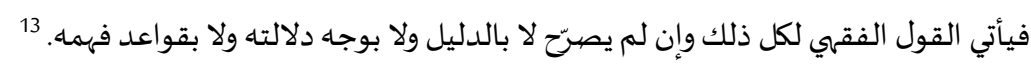

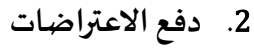

وحيث كانت ظواهر تلك الأقوال معرّضة للاحتمال بما يمكّن المخالف من الاعتراض على الحكم، سعى ابن الشاط إلى افتراضها

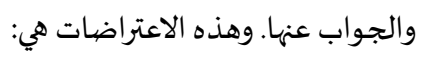

21-5/6 المعيار، 10 وقد أورد ابن الشاط قول كل من ابن الحارث، وابن عبد البرّ، وما ورد في العتبية. ينظر: ما تقدم في أول النازلة.

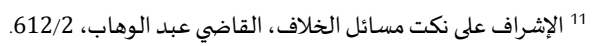

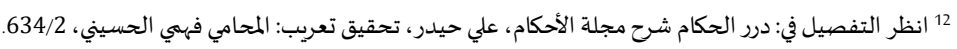

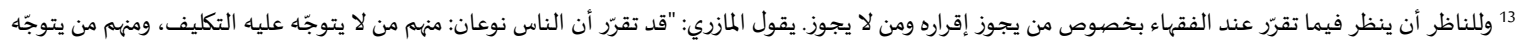

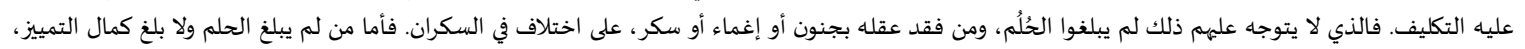

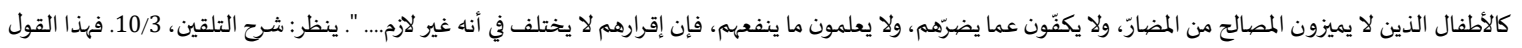

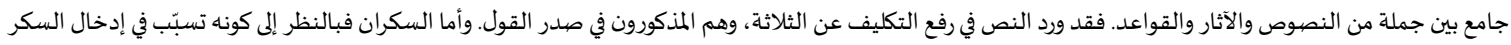


الاعتراض الأول: نقول المذهب إنما هي في الإقرار لمعيّن:

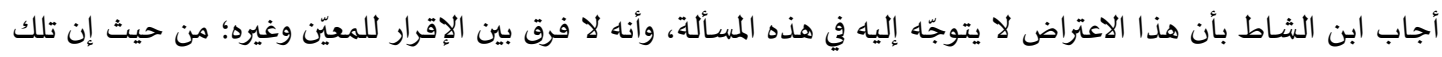

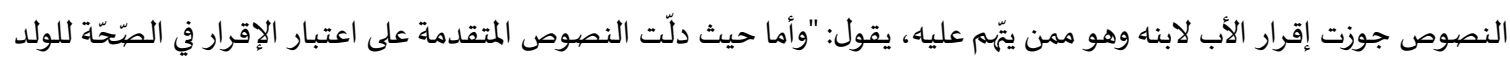

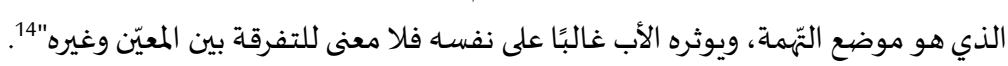

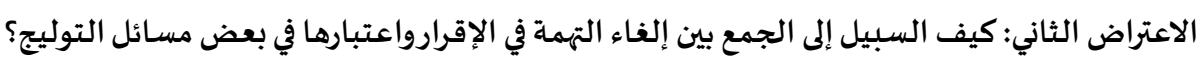

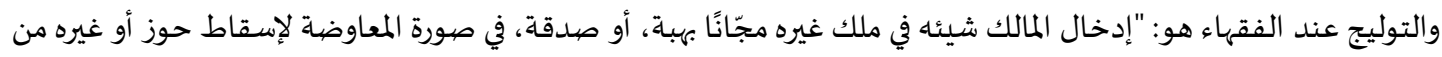

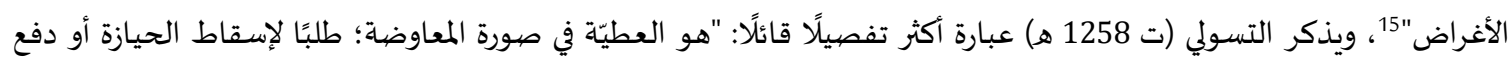

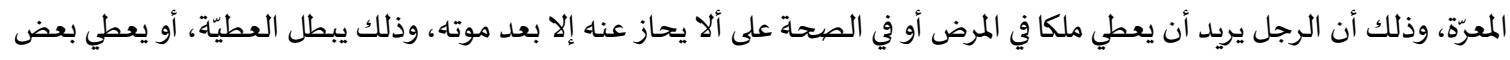

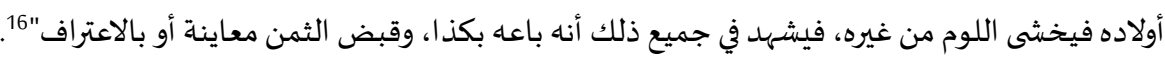

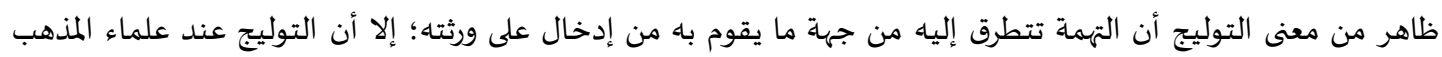

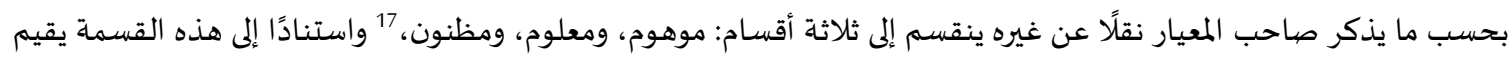

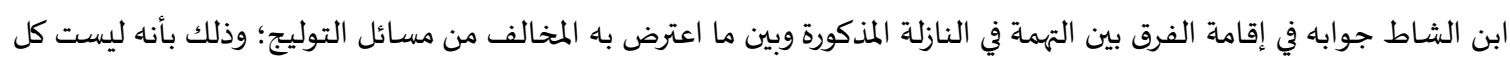

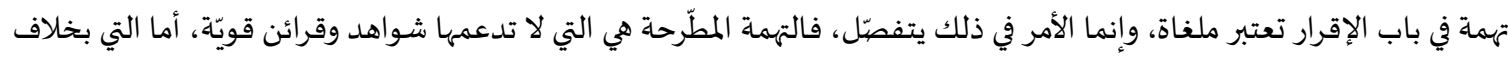

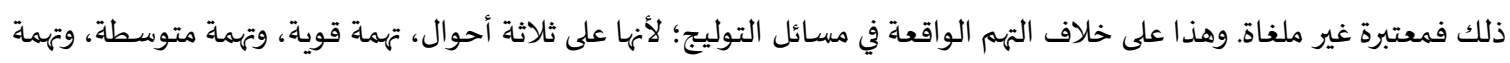

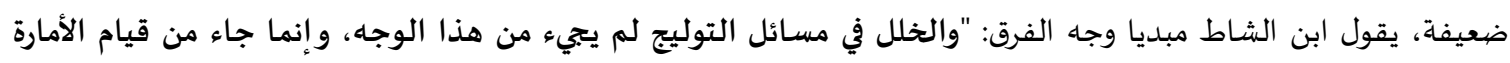

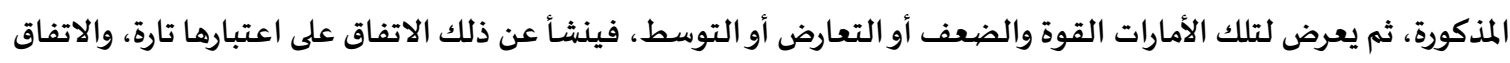

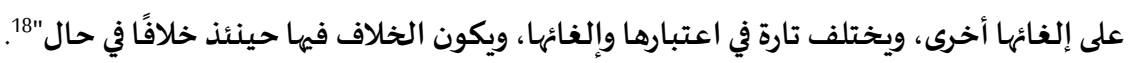

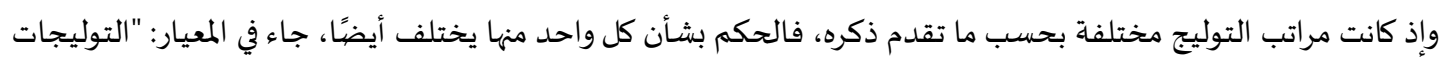

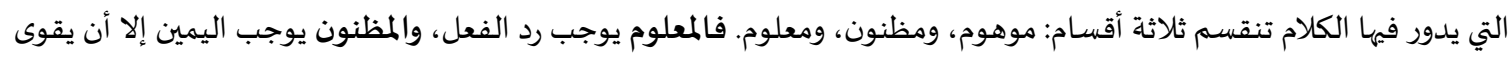

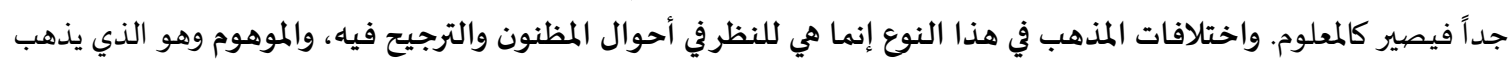

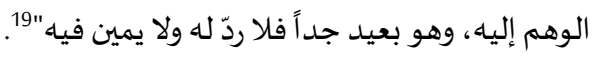

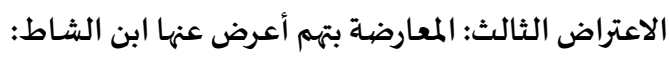

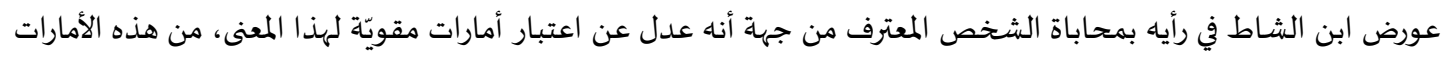

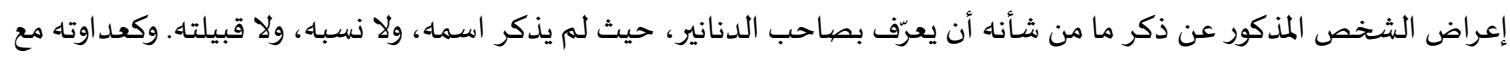

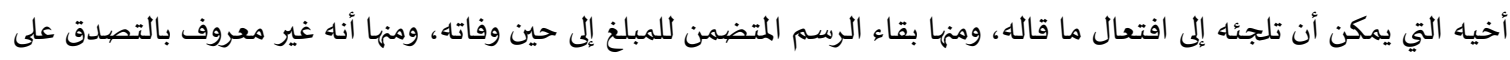

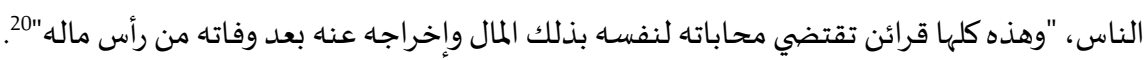

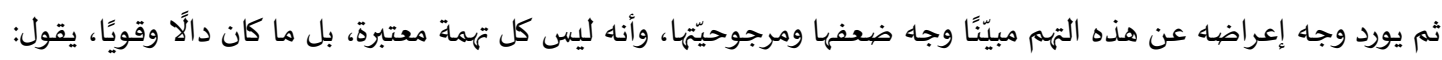

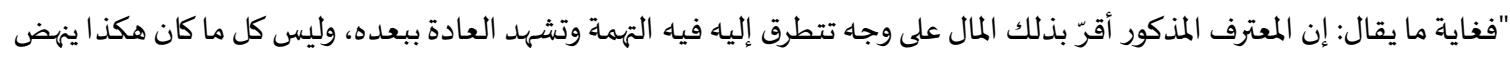

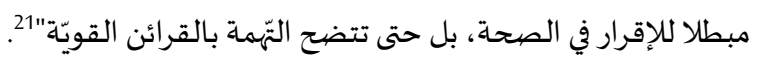
الاعتراض الر ابع: الاعتراض بالقياس:

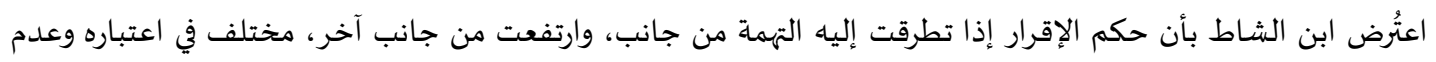

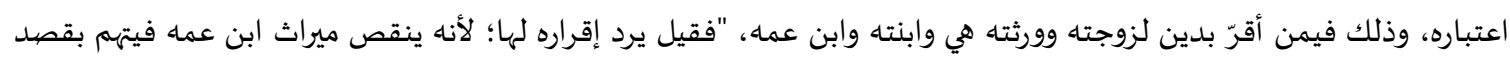

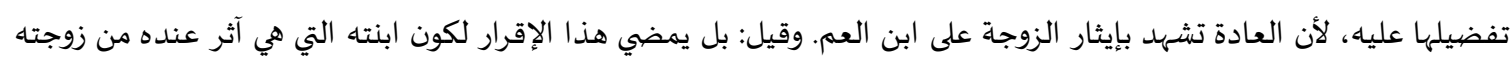
يلحقها من هذا الإقرار انتقاص من حقّها أيضًا"22.

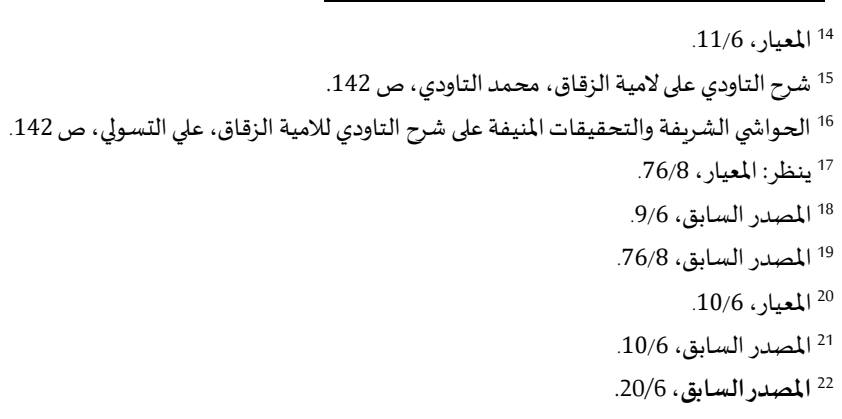


يدفع ابن الشـاط هذا القياس بأنه "لا يصحّ دخول هذا الخلاف في مسألتنا لقيام الفارق بين البنت والأخ، وذلك أن وجود الولد

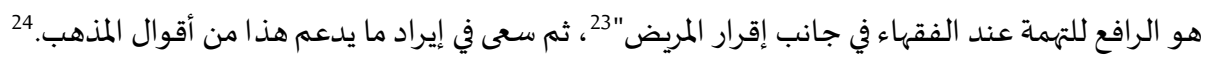

الاعتراض الخامس: وجوب بعمومات المدوّنة:

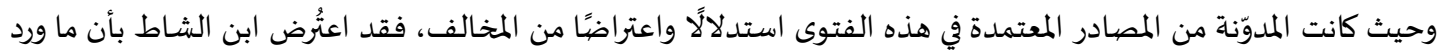

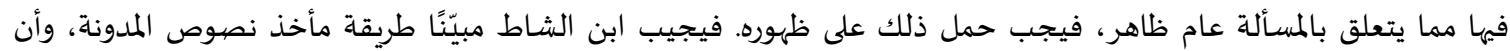

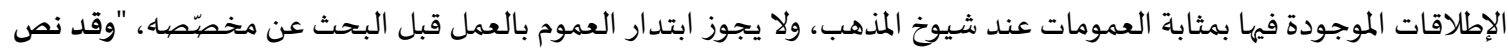

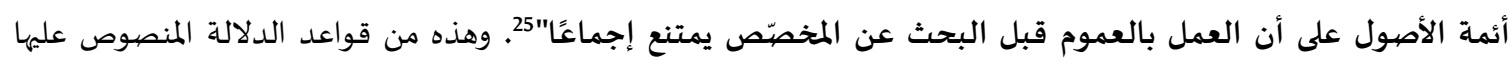
عندهم. 26

الاعتراض السادس: عدم مراعاة حال الوباء الذي وقع فيه الحادث:

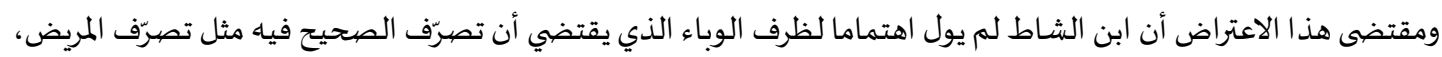

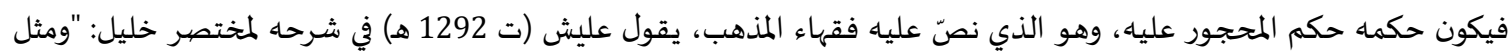

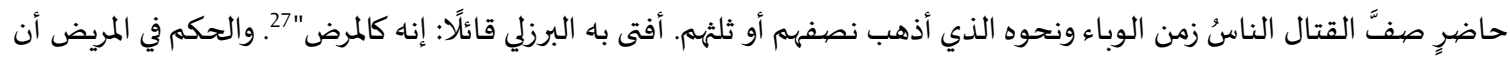

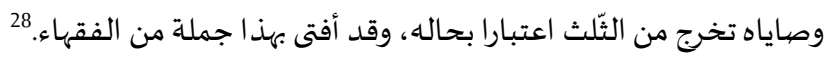

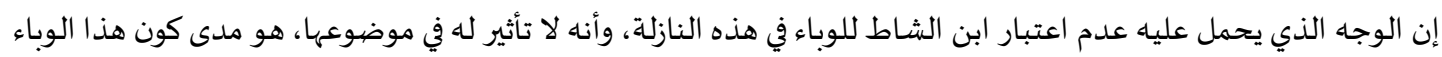

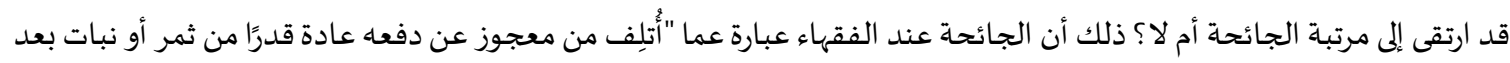

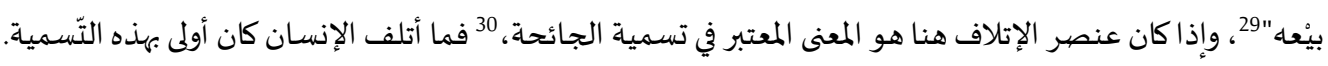

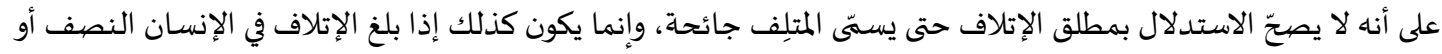
الثلث بحسب ما يعطيه نصّ خليل السابق، وأن يبلغ الثّلثَ في الثّمار أيضًا حسبما نصّّ عليها علماء المذهب.

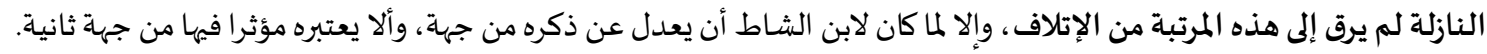

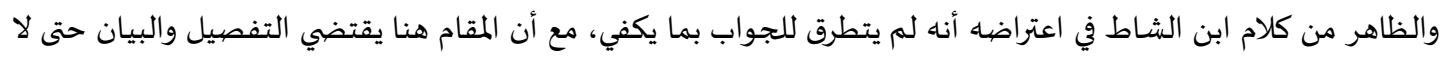
يلتبس الأمر في ذلك على القارئ. لقد حاد ابن الشـاط عن ذكر ذلك مستعملًا آلية الانتقال 32 المعروفة لدى الجدليّيّن؛ إذ سار في ذكر أمور أخرى لا تعلّق لها

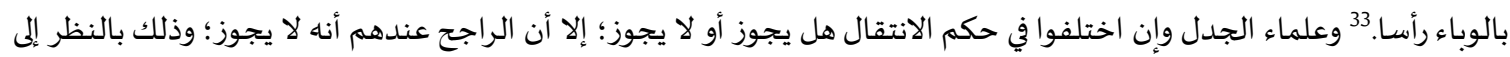

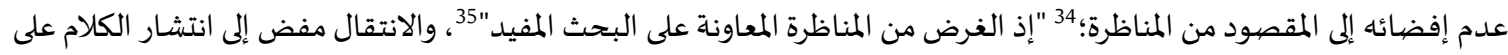

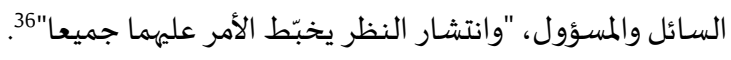
ثانياً: النوازل والاجتهاد:

إن أبرز ما يستخلص من فتوى ابن الشاط، سواء فيما أصيّله من جواب، أو فيما اعترض بهاء على غيره ممن سبقها إلى القول فيها،

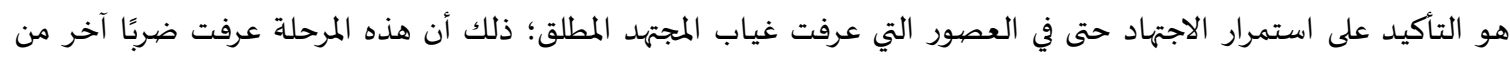

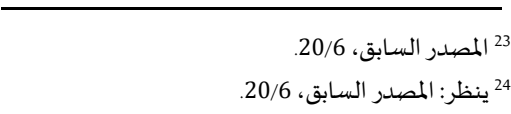

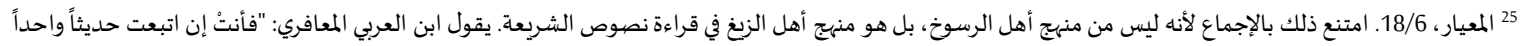

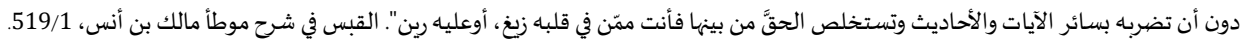

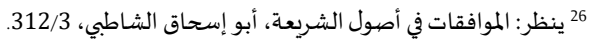

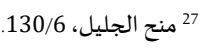

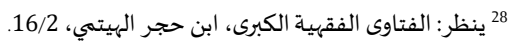

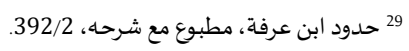

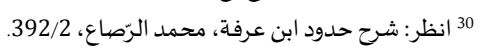

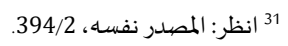

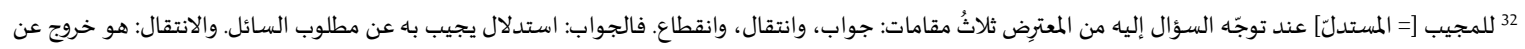

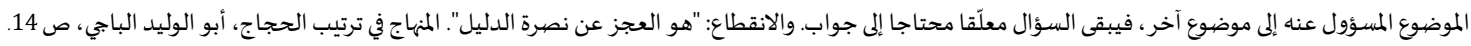

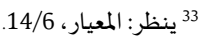

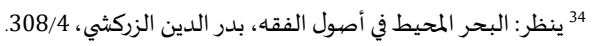

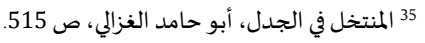

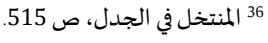


المجتهدين، وهم أولئك الذين يجتهدون داخل المذهب الفقهي الواحد، ترجيحا بين أقواله ورواياته، وتشهيرًا لبعض الأقوال على بعض،

$$
\text { وهذا تصرّف معروف لدى الفقهاء من مختلف المذاهب الفقهيّة. }
$$

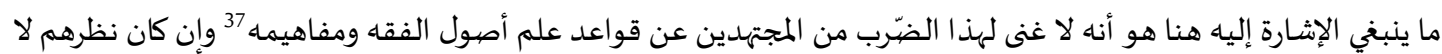

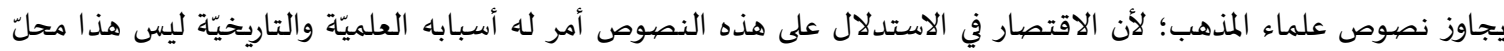

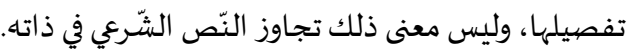

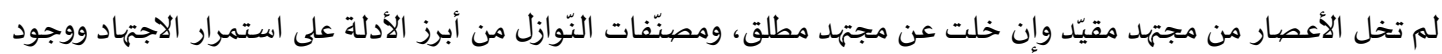

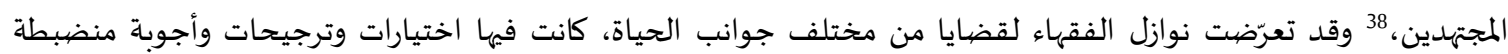
لضوابط علم أصول الفقه، وهذا لا يصدر إلا عن مجتهد.

الخاتمةة:

ما تقدّم كان عبارة عن حصيلة قراءة مختصرة لجواب ابن الشاط، حاولنا من خلالها فحص جوابه وتحليله بحسب ما سنحت

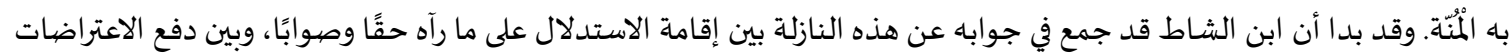

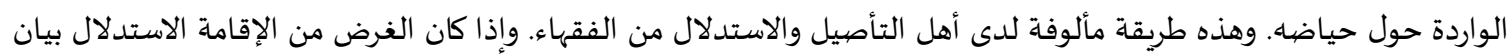

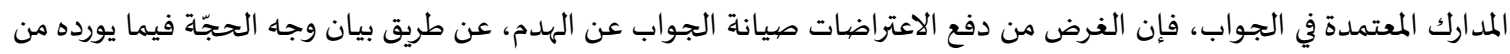

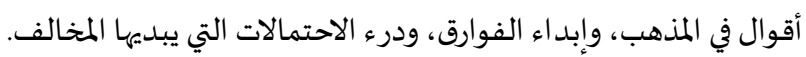

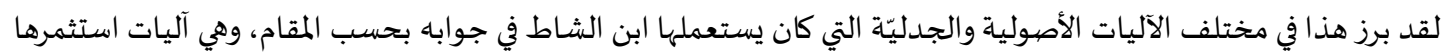

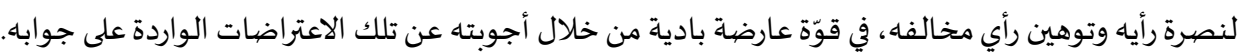

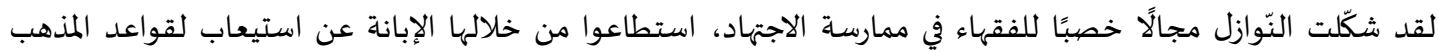

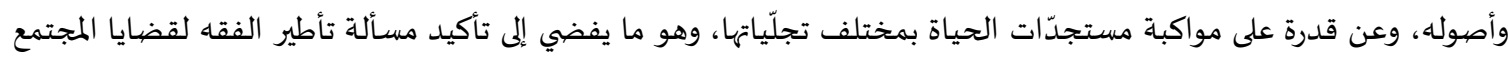

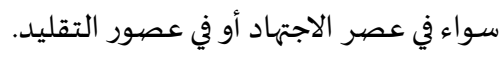

37 تم التطرق في مقال سابق لحاجة المفتي من داخل المذهب إلى علم أصول الفقه. انظر: أثر علم الأصهول في صناعة المفتي: المعرفة والمنهج، عبد الحميد الراقي، المجلة الإلكترونية

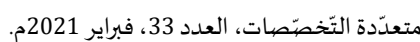

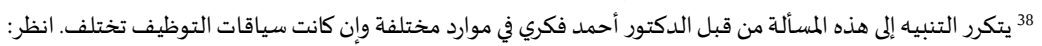

- I. FIKRI, Pragmatic in Islamic Law, in Middle East Studies Beyond Dominant Paradigm, Syracuse University Press, p. 11-15. (2014).

- $\quad$ FIKRI, Rethinking the Taqlid Hegemony: An Institutional, Longue-Duree Approach, Journal of American Oriental Society, 126.4, (2016).

- FIKRI, Rethinking the Taqlid-Ijtihad Dichotomy: A Conceptual -Historical Approach, Journal of American Oriental Society, 126.2, (2016).

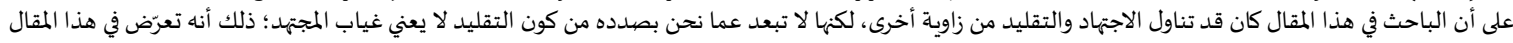

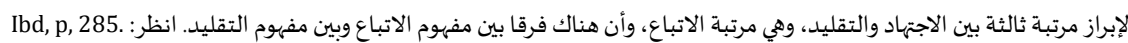


1. الباجي، أبو الوليد (2003). المنهاج في ترتيب الحجاج. تحقيق عبد المجيد تركي، الطبعة الثالثة، دار الغرب الإسلامي-تونس.

2.

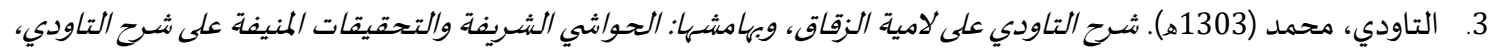

علي التسولي. الطبعة الأولى، المطبعة التونسية.

4 4. الجويني، عبد الملك (1992). البرهان في أصول الفقها. تحقيق عبد العظيم الدّيب، الطبعة الثالثة، دار الوفاء للطباعة والنشر والتوزيع-

المنصورة.

5. حيدر، علي (د.ت). درر الحكام شرح مجلة الأحكام. تحقيق تعريب: المحامي فهي الحسيني، دار الكتب العلمية-لبنان.

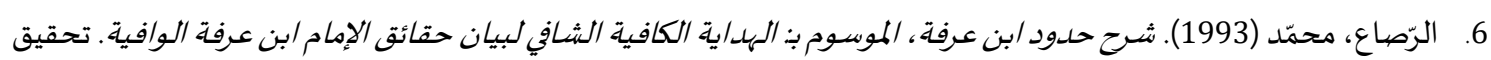

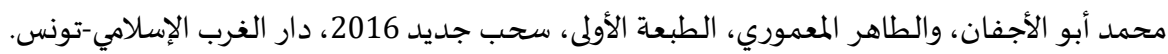

7.

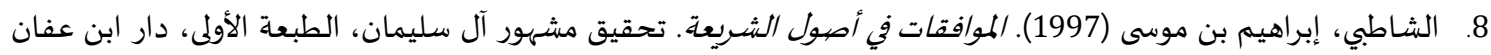

$$
\begin{aligned}
& \text { للتوزيع والنشر - القاهرة. } \\
& \text { 9. عليش، محمد (1989). منح الجليل شرح مختصر خليل. دار الفكر- بيروت. }
\end{aligned}
$$

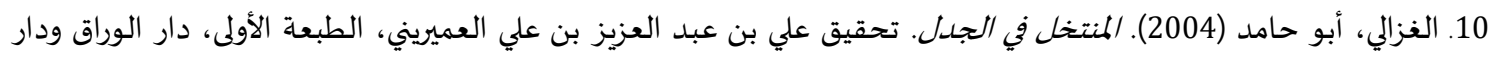

$$
\text { النيربين- الرياض. أنو حام. }
$$

11. الغزالي، أبو حامد محمد (1993). المستصفى من علم الأصول. تحقيق: محمد عبد السلام عبد الشافي، الطبعة الأولى، دار

الكتب العلمية- بيروت.

12. المازري، أبو عبد الله (2008). شرح التلقين. تحقيق محمد المختار السلامي، الطبعة الأولى ، دار الغرب الإسلامي-تونس.

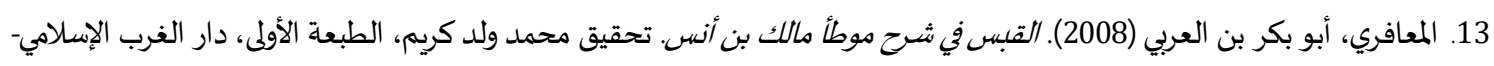

$$
\begin{aligned}
& \text { تونس. } \\
& \text { 14. الهيتمي، ابن حجر (د.ت). الفتاوى الفقهية الكبابى. بدون تاريخ، دار الفكر. }
\end{aligned}
$$

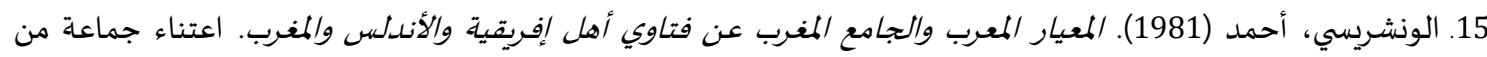

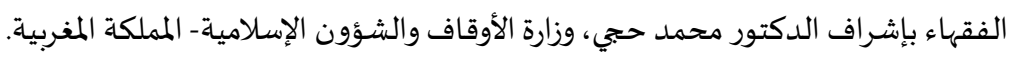

ثانياً: المقالات:

1. الراقي، عبد الحميد (2021). أثر علم الأصهول في صناعة المفتي: المعرفة والمنهج، عبد الحميد الراقي، المجلة الإلكترونية متعدّدة التّخصِّصات:

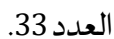

2. FIKRI, (2014). Pragmatic in Islamic Law, in Middle East Studies Beyond Dominant Paradigm. Syracuse University Press.

3. FIKRI, (2016). Rethinking the Taqlid-Ijtihad Dichotomy: A Conceptual -Historical Approach. Journal of American Oriental Society, 136(2): 285. https://doi.org/10.7817/jameroriesoci.136.2.285

4. FIKRI, Ibrahim. (2016). Rethinking the Taqlid Hegemony: An Institutional, Longue-Duree Approach. Journal of American Oriental Society, 136(4): 801. https://doi.org/10.7817/jameroriesoci.136.4.0801

5. Stearns.J. (2011). The legal Status of Science in The Muslim World in The Early Modern Period: An Initial Consideration of Fatwas from Three Magribi Sources. In: The Islamic scholarly tradition, studies in history, law, and thought in honor of Professor Michael Allan Cook. BRILL. 
المجلة الدولية للدراسـات الإسلامية المتخصصية

International Journal of Specialized Islamic Studies (SIS)

www.refaad.com

Journal Homepage: https://www.refaad.com/views/SIS/Home.aspx

ISSN: 2617-6246(Online) 2617-6238(Print)

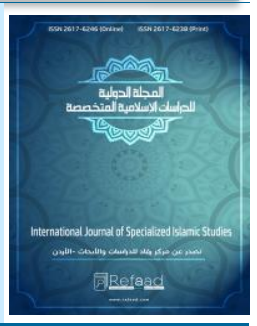

\title{
Ibn Al-shat's answer to (Nazila) in the time of the epidemic: A study in its foundations
}

\author{
Abdelhamid Raki \\ University Mohamed Ben Zayed of the Human Sciences \\ Almuwatta Center of Studies and Teaching \\ hamidraki10@gmail.com
}

Received: 23/5/2021 Revised: 20/6/2021 Accepted: 27/6/2021 DOI: https://doi.org/10.31559/SIS2021.6.1.2

Abstract: The aim of this research is showing the principles which Ibn SHAT based on his fatwa in the epidemic time. Those principles range between two types, one of them is the rules which are the foundations of fatwa, and the other is the dialectical mechanisms which ibn shat used them in order to opposite to the Alokbani' answer. The research also aims to emphasis -from the deference of fatawa- the continuity of ijtihad despite of disappear of the absolute mujtahid.

Keywords: Alnawazil; The principles of Jurisprudence; Ijtihad; The Malikite Doctrine.

\section{References:}

1. Albajy, Abw Alwlyd (2003). Almnhaj Fy Trtyb Alhjaj. Thqyq 'bd Almjyd Trky, Altb'h Althalthh, Dar Alghrb Aleslamy-Twns.

2. Albghdady, 'bd Alwhab (1999). Aleshraf 'la Nkt Msa'el Alkhlaf. Thqyq Alhbyb Bn Tahr, Altb'h Alawla, Dar Abn Hzm.

3. Altawdy, Mhmd (1303h). Shrh Altawdy 'la Lamyh Alzqaq, Wbhamshha: Alhwashy Alshryfh Walthqyqat Almnyfh 'la Shrh Altawdy, 'ly Altswly. Altb'h Alawla, Almtb'h Altwnsyh.

4. Aljwyny, 'bd Almlk (1992). Albrhan Fy Aswl Alfqh. Thqyq 'bd Al'zym Aldyb, Altb'h Althalthh, Dar Alwfa' Lltba'h Walnshr Waltwzy'- Almnswrh.

5. Hydr, 'ly (D.T). Drr Alhkam Shrh Mjlt Alahkam. Thqyq T'ryb: Almhamy Fhmy Alhsyny, Dar Alktb Al'lmyhLbnan.

6. Alrsa', Mhmd (1993). Shrh Hdwd Abn 'rfh, Almwswm B: Alhdayh Alkafyh Alshafy Lbyan Hqa'q Alemam Abn 'rfh Alwafyh. Thqyq Mhmd Abw Alajfan, Waltahr Alm'mwry, Altb'h Alawla, Shb Jdyd 2016, Dar Alghrb Aleslamy-Twns.

7. Alzrkshy, Mhmd Bn 'bd Allh (2000). Albhr Almhyt Fy Aswl Alfqh. Thqyq D. Mhmd Mhmd Tamr, Dar Alktb Al'lmyh- Byrwt.

8. Alshatby, Ebrahym Bn Mwsa (1997). Almwafqat Fy Aswl Alshry'h. Thqyq Mshhwr Al Slyman, Altb'h Alawla, Dar Abn 'fan Lltwzy' Walnshr- Alqahrh.

9. 'lysh, Mhmd (1989). Mnt Aljlyl Shrh Mkhtsr Khlyl. Dar Alfkr- Byrwt.

10. Alghzaly, Abw Hamd (2004). Almntkhl Fy Aljdl. Thqyq 'ly Bn 'bd Al'zyz Bn 'ly Al'myryny, Altb'h Alawla, Dar Alwraq Wdar Alnyrbyn- Alryad.

11. Alghzaly, Abw Hamd Mhmd (1993). Almstsfa Mn 'Im Alaswl. Thqyq: Mhmd 'bd Alslam 'bd Alshafy, Altb'h Alawla, Dar Alktb Al'lmyh- Byrwt. 
12. Almazry, Abw 'bd Allh (2008). Shrh Altlqyn. Thqyq Mhmd Almkhtar Alslamy, Altb'h Alawla, Dar Alghrb Aleslamy-Twns.

13. Alm'afry, Abw Bkr Bn Al'rby (2008). Alqbs Fy Shrh Mwta Malk Bn Ans. Thqyq Mhmd Wld Krym, Altb'h Alawla, Dar Alghrb Aleslamy- Twns.

14. Alhytmy, Abn Hjr (D.T). Alftawa Alfqhyh Alkbra. Bdwn Tarykh, Dar Alfkr.

15. Alwnshrysy, Ahmd (1981). Alm'yar Alm'rb Waljam' Almghrb 'n Ftawy Ahl Efryqyh Walandls Walmghrb. A'tna' Jma't Mn Alfqha' Beshraf Aldktwr Mhmd Hjy, Wzart Alawqaf Walsh'wn Aleslamyh- Almmlkh Almghrbyh. 